\title{
As apropriações da obra de Pierre Bourdieu no campo educacional brasileiro, através de periódicos da área*
}

\author{
Afrânio Mendes Catani \\ Faculdade de Educação, Universidade de São Paulo
}

\author{
Denice Bárbara Catani \\ Faculdade de Educação, Universidade de São Paulo
}

\author{
Gilson R. de M. Pereira
}

Faculdade de Educação, Universidade do Estado do Rio Grande do Norte

\begin{abstract}
[...] para entender a "recepção" [de um autor] deve-se entender as forças da não recepção, a recusa em saber. [...] Sartre, em uma nota de A crítica da razão dialética disse, a propósito de suas leituras juvenis de Marx (que não se lia na universidade): "eu compreendia tudo e não compreendia nada”. Quer dizer que há uma compreensão, um fazer como se se compreeendera, uma falta de compreensão fundada em resistências profundas.
\end{abstract}

P. Bourdieu

O que é fazer falar a um autor?

A propósito de Michel Foucault.

O presente artigo articula os resultados já obtidos através de pesquisa que se realiza acerca da obra de Pierre Bourdieu, buscando compreender as várias modalidades de apropriação que marcaram o ingresso dos estudos do sociólogo francês no campo educacional brasileiro. Com a finalidade de tornar exeqüível esse

* Trabalho apresentado na 23 Reunião Anual da ANPEd, Caxambu (MG), set. 2000, no GT Sociologia da Educação. estudo, opera-se por etapas que prevêem o exame das especificidades brasileiras da leitura de Bourdieu nos periódicos especializados em educação, na utilização do autor em teses, dissertações e estudos publicados sob a forma de livros, em trabalhos apresentados em congressos, no movimento editorial do campo e na bibliografia de cursos universitários. Essa divisão, que diferencia as fontes mediante as quais é possível ter acesso aos processos de apropriação da obra do autor, não pretende autonomizar as diferentes instâncias de uma mesma dinâmica característica de um espaço de produção intelectual. Assim, mantendo a atenção para com a simultaneidade, as relações e a interdependência dessas instâncias, pode-se proceder ao estudo específico da produção divulgada em vinte periódicos educacionais de circulação nacional e amplamente reconhecidas, embora algumas já tenham tido sua publicação interrompida. O período escolhido para exame foram os anos de 1971 a 2000 e, nos vinte periódicos examinados, foram localizados 355 trabalhos (dentre os quais seis resenhas) com referências à obra de Bourdieu. Como se pretendeu tratar da apropriação no campo educacional brasileiro, analisaram-se ape- 
nas os textos de autores nacionais com referências ao sociólogo (totalizando 288 artigos); do conjunto de trabalhos localizados, foram descartados 67 escritos de autores estrangeiros publicados, no mesmo período, nas revistas consultadas. ${ }^{1}$

Além disso, o presente trabalho levou em consideração, em grande parte, os ensinamentos contidos na análise realizada por Loïc Wacquant (1993) sobre as condições de recepção da obra de Bourdieu nos Estados Unidos. Escreve ele, citando o próprio Bourdieu (1993), que

se é verdade que o sentido de uma obra (artística, literária, filosófica etc.) muda automaticamente a cada mudança no campo em que está situada para o espectador ou leitor', então a adequada compreensão de um determinado autor impõe um duplo trabalho de elucidação: de suas idéias e do universo intelectual no qual elas chegam a circular. Requer que codifiquemos o espaço mental do autor - isto é, as categorias e postulados que o sustentam ou sua maneira de pensar e teorias substantivas - e requer, também, que consigamos alguma informação acerca do espaço acadêmico no qual seus escritos estão inseridos (Wacquant, 1993, p. 235).

${ }^{1}$ Os periódicos consultados foram os seguintes: ANDE, $\mathrm{n}^{\circ} 1-$ 21, São Paulo, 1981/1995; Cadernos CEDES, nº 1-50, Campinas (SP), 1980/2000; Cadernos de Pesquisa, n 1-110, São Paulo, 1971/2000; Contexto e Educação, no 1-53, Ijuí (RS), 1986/1999; Educação \& Filosofia, no 1-25, Uberlândia (MG), 1986/1999; Educação \& Realidade, v. 1-24, Porto Alegre (RS), 1976/1999; Educação e Seleção, n 1-20, São Paulo, 1980/1989; Educação \& Sociedade, $\mathrm{n}^{\circ}$ 1-70, Campinas (SP), 1978/2000; Educação em Debate, no 1-37, Fortaleza (CE), 1978/1999; Educação em Revista, no 1-30, Belo Horizonte (MG), 1985/1999; Em Aberto, no 1-70, Brasília (DF), 1981/1996; Estudos em Avaliação Educacional, $\mathrm{n}^{\circ}$ 1-19, São Paulo, 1990/1999; Fórum Educacional, v. 1-14, Rio de Janeiro, 1977/1990; Idéias, n 1-30, São Paulo, 1988/1998; ProPosições, no 1-22, Campinas (SP), 1990/1997; Revista Brasileira de Administração da Educação, RBAE, v. 1-12, Porto Alegre (RS), Brasília (DF), 1983/1996; Revista Brasileira de Educação, no 011, São Paulo, 1995/1999; Revista Brasileira de Estudos Pedagógicos, Rbep, n 117-193, Brasília (DF), 1970/2000; Revista da Faculdade de Educação, v. 1-24, São Paulo, 1975/1998; Teoria \& Educação, nº 1-6, Porto Alegre (RS), 1990/1992.
Evidentemente, nos informamos acerca das idéias e do universo intelectual no qual as idéias de Bourdieu circulam, bem como procedemos à decodificação do espaço mental do autor. Para isso, além da leitura da obra do pensador francês, valemo-nos de bons comentaristas: Miceli (1987; 1999), Ortiz (1983), Pinto (2000). Utilizamo-nos, igualmente, de várias análises empíricas desenvolvidas por Bourdieu e pelos seus colaboradores.

Escolhemos falar em apropriação da obra de Bourdieu para, justamente, indicar a variedade das formas de recepção e as formas peculiares de invenção na leitura que se fez desse autor. O sentido do termo - parte do esquema conceitual forjado por Roger Chartier (1998) para explicitar os processos de produção de sentido que configuram a leitura como criação - matiza a compreensão das várias "interpretações" feitas entre nós. Chartier refere-se ao conceito sustentando que

[...] a apropriação tal como a entendemos visa a uma história social dos usos e interpretações referidos a suas determinações fundamentais e inscritos nas práticas específicas que os produzem. Dar, assim, atenção às condições e aos processos que, muito concretamente, conduzem as operações de construção do sentido (na relação de leitura e nos outros casos também), é reconhecer, contra a antiga história intelectual, que nem as inteligências nem as idéias são descarnadas e, contra os pensamentos do universal, que as categorias dadas como invariantes, sejam filosóficas ou fenomenológicas, estão por se construir na descontinuidade das trajetórias históricas. (Chartier, 1998, p. 74)

O próprio Bourdieu não se afasta dessa interpretação na oportunidade em que examina as relações mantidas pelos indivíduos com as práticas culturais em "Lecture, lecteurs, lettrés, littérature" (1987) e ao dialogar com R. Chartier (Bourdieu e Chartier, 1985) acerca da questão da leitura ou do consumo cultural.

Assim é que buscamos explicitar as características da apropriação feita do pensamento de Bourdieu no Brasil, mediante a análise dos textos nos quais há referências ao autor e incorporação de conceitos e/ou assimilação de seu modo de trabalho. Os textos analisados permitem identificar três categorias, de acordo 
com os tipos de apropriação que se evidenciaram. A forma mais freqüente de apropriação é designada como apropriação incidental, caracterizada por referências rápidas ao autor, geralmente do livro A Reprodução (constituem 67\% dos artigos consultados). Nessa modalidade de apropriação, são freqüentes as seguintes ocorrências: é comum o sociólogo ser arrolado nas referências bibliográficas e não aparecer mencionado no corpo do texto; vir referido apenas de passagem, junto com outros autores (em geral, Althusser, Baudelot e Establet, Bowles e Gintis), quase sempre de modo classificatório ("reprodutivista"); surgir em notas não substantivas. Nas apropriações incidentais, não é possível estabelecer relação entre a argumentação empreendida no texto e a referência, ou então a menção guarda relação muito tênue com o argumento desenvolvido. Classificamos a outra forma sob a denominação de apropriação conceitual tópica, caracterizada pelo fato de deixar entrever a utilização, conquanto não sistemática, de citações e eventualmente de conceitos do autor, como o de capital cultural, por exemplo (constituem $18 \%$ dos artigos consultados). Nessa forma de apropriação, as aquisições conceituais do sociólogo são mobilizadas, com maior ou menor intensidade, para reforçar argumentos ou resultados obtidos e desenvolvidos num quadro terminológico que não necessariamente é o do autor. Ampliam o leque de obras citadas, aparecendo textos como A economia das trocas simbólicas, $O$ poder simbólico, Coisas ditas etc. A terceira forma recebe o nome de apropriação do modo de trabalho, constituindo-se em maneiras de apropriação reveladoras da utilização sistemática de noções e conceitos do autor, tais como campo, estratégia, habitus etc., bem como mostram preocupação central com o modus operandi da teoria (construção do objeto, pensar relacional, análise reflexiva, objetivação do sujeito objetivante etc.). Nessa forma de apropriação (15\% dos artigos consultados), acionamse os utensílios teóricos desenvolvidos por Bourdieu em realidades empíricas precisas, sendo maior a diversidade de obras referidas e, inclusive, aparecem menções às Actes de la Recherche en Sciences Sociales, periódico fundado por Bourdieu em 1975 e por ele dirigido até hoje. Nossa estratégia de trabalho, mais do que pretender avaliar a justiça ou adequação das apropriações, apela a esse mesmo conceito de apropriação e à maneira pela qual o próprio Bourdieu entende a diversidade da produção das práticas culturais para tentar mostrar também algo das condições nas quais o autor foi lido.

Os primeiros textos de Bourdieu traduzidos no Brasil são dois artigos que aparecem em coletâneas publicadas em 1968 (Problemas do estruturalismo, organizada por Jean Pouillon, e Sociologia da juventude, organizada por Sulamita de Britto, ambas publicadas pela editora Zahar). No entanto, ele começaria a ser mais extensivamente lido em meados da década de 1970, quando outros artigos de sua autoria surgiram em A economia das trocas simbólicas, antologia organizada em 1974 por Sergio Miceli, e em 1975, quando da primeira edição brasileira de $A$ Reprodução. Tais publicações, mais divulgadas que as anteriores, tornariam alguns importantes trabalhos do sociólogo acessíveis ao público leitor interessado em questões sociológicas e educacionais, sobretudo professores e estudantes universitários. Na mesma época, o artigo de Bourdieu "Condição de classe e posição de classe" seria incluído na coletânea Hierarquias em classes, organizada por Neuma Aguiar. Ainda nos anos de 1970, dois outros artigos de Bourdieu fariam parte da coletânea organizada por José C. Garcia Durand (Educação e hegemonia de classe), e no mesmo período seria lançada a tradução de Algérie 60 , que no Brasil receberia o sugestivo título $O$ desencantamento do mundo. Se nessa década Bourdieu causaria certo impacto, embora restrito, na produção sociológica e antropológica universitária, passaria, entretanto, relativamente desapercebido no campo educacional brasileiro, que não responderia com maior entusiasmo à chegada de um sociólogo que, mesmo na França e na Europa, era tido como difícil e não oferecia muitas armas para as lutas acadêmicas da época, em geral voltadas à militância política.

Até meados da década de 1970, as referências a Bourdieu são incidentais e esporádicas (nessa década aparecem 15 menções ao autor nos periódicos). Publica-se um texto com referência ao sociólogo francês na Revista Brasileira de Estudos Pedagógicos (Capalbo, 
1974), e em Cadernos de Pesquisa registram-se a resenha de La Reproduction, ainda não traduzido naquele momento (Barreto, 1972), e outros poucos artigos nos quais é possível identificar apropriações incidentais de sua obra (Barreto, 1975; Barroso \& Mello, 1975; Gouveia, 1976). Nos anos finais dessa década, seriam ainda publicados nove artigos em $E d u$ cação \& Sociedade com referências a Bourdieu: em geral incidentais, e o artigo de Luiz Antônio Cunha (1979), que desencadearia, pouco depois, breve polêmica nas páginas de Cadernos de Pesquisa (Cunha, 1982; Durand, 1982). ${ }^{2}$ O fato é que se a obra de Bourdieu ativou direta ou indiretamente estudos no campo educacional brasileiro nos anos de 1970, isso deve ser creditado muito mais a alguns conceitos e resultados analíticos obtidos pelo sociólogo - proveitosos, sem dúvida, para dar conta de uma realidade educacional brasileira que já na época parecia cada vez mais excludente - do que propriamente a uma incorporação sistemática do modo de fazer pesquisa do autor francês.

Os anos de 1979 a 1983 seriam decisivos para a forma da ulterior apropriação de Bourdieu no campo educacional brasileiro (dois marcos nessas datas: em 1979, a publicação do artigo de Cunha acima mencionado e, em 1983, uma coletânea de artigos de Saviani). Durante esses anos, há o início de uma operação caracterizada pela cobrança de pressupostos políticos na leitura de Bourdieu. É uma operação de deslocamento: retirada dos quadros científicos mais amplos que lhe conferem sentido, a obra de Bourdieu, lida sobretudo a partir de A Reprodução, passa a ser objeto de controvérsias políticas no campo educacional brasileiro. Isso ocorre quando, na oportunidade, os textos do sociólogo francês são aprisionados na dicotomia muito em voga da "reprodução x transformação" (que na passagem dos anos de 1980 para os de 1990 seria transmutada na dicotomia "reprodução x resistência", cf. Teoria \& Educação, n. ${ }^{\circ}$ 1, cujo título geral é "Teorias da reprodução e da resistência”). Reconhece-se

${ }^{2}$ Nesse mesmo número, os Cadernos de Pesquisa publicaram também o artigo bastante crítico de Vincent Petit, intitulado "As contradições de "A Reprodução"”. que Bourdieu passa a ser considerado um autor crítico, mas politicamente desmobilizador: sua teoria, se possibilita instrumentos para a crítica da função desempenhada pela escola na sociedade capitalista, não fornece armas para a ação, limita-se à constatação da dimensão reprodutivista da escola, não dá conta das contradições da realidade, enfim, desmobiliza. ${ }^{3} \mathrm{~A}$ imposição dessa problemática tem como uma das consequiências concentrar a atenção nessa dimensão da leitura, afastando-se da compreensão dos propósitos e da lógica da obra de Bourdieu e condicionando fortemente, como já afirmado, a forma da apropriação do autor no campo educacional brasileiro. ${ }^{4}$

3 "Tais categorias [das teorias da reprodução e dos aparelhos ideológicos do Estado] foram úteis para o desvelamento do caráter ideológico da ação escolar, e para a denúncia de seu papel reforçador das desigualdades sócio-econômicas [sic.] em contextos sociais como os da América Latina. Recheadas das contradições de um momento histórico concreto e específico, esses modelos teóricos tornam-se, entretanto, frágeis orientadores da ação prática. [...] Que espaço existiria para uma ação escolar transformadora na ótica das teorias reprodutivistas da educação? Provavelmente pouco ou nenhum" (Mello, 1983, p. 5-6). Saviani (1983, p. 25) cita frase, bastante sintomática, de Snyders: "Bourdieu-Passeron ou a luta de classes impossível". Referindo-se às pesquisas educacionais brasileiras nos anos de 1970, Goergen (1986, p. 7) fala em "pessimismo e desânimo que via na educação nada mais que um engenho reprodutor dos interesses das classes dominantes", e atribui esse "imobilismo reprodutivista" às "idéias de Bourdieu e Passeron".

${ }^{4}$ Seria suficiente reter alguns excertos para dar conta do que se está dizendo: “A obra de Bourdieu e Passeron, propondo para as escolas e para os sistemas educacionais um papel reprodutor das relações de desigualdades e de opressão [...]" (Velloso, 1985, p. 112). Ao referir-se à sociologia de Bourdieu, Mello (1979) comenta: "É o caso de algumas tendências mais recentes da sociologia da educação que emprestam à ação pedagógica - exercida sob o inexorável controle da classe dominante - um poder quase absoluto, de cuja violência não existiria escapatória” (p. 71). Essas interpretações prolongar-se-iam por muito tempo e, já tardiamente, chegam a formulações como: "A violência simbólica, enquanto instância que ocorre nas escolas, é o principal vilão da história? Não. A violência simbólica é apenas o inocente útil, manipulado pelos poderes públicos na direção de impedir a compreensão da verdadeira violência" (Whitaker, 1994, p. 35). 
Ainda acerca de A Reprodução, Bento Prado Jr. (1980) foi um dos melhores intérpretes do sociólogo francês no Brasil, sendo seu texto contrastante com a maioria das análises realizadas por aqui. Muitas críticas ocorreram na França, no princípio dos anos de 1970, acerca do referido livro, tendo algumas delas conseguido razoável difusão entre nós. ${ }^{5}$ Prado Jr. observa que tais críticas constituem-se, principalmente, em objeções de inspiração marxista,

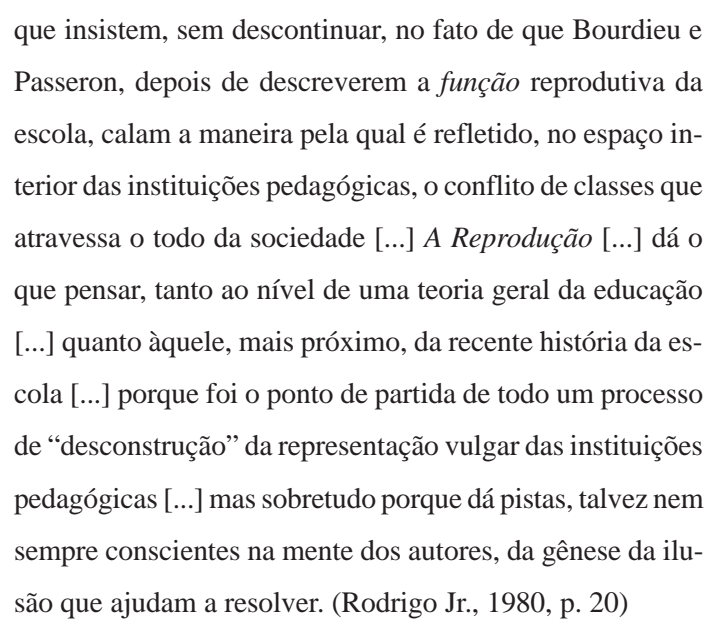

Prado Jr. destaca, ainda, que os autores estabelecem uma teoria geral da "violência simbólica" e, simultaneamente, propõem uma explicação do funcionamento das instituições escolares da França, elaborando a análise de uma Faculdade de Letras, mostrando que o universitário, ao dominar o código lingüístico, converte-se numa espécie de mandarim. E o que vai dar o tom é, justamente, esse código lingüístico burguês (constituído fundamentalmente no quadro da socialização primitiva, no âmbito familiar), "com seus cacoetes, seus idiotismos, sua particularidade". Reencontrado nas salas de aula pelos "futuros notáveis" (ou, para se valer de outra obra de Bourdieu,

${ }^{5}$ As mais conhecidas são as seguintes: Antoine Prost, Une sociologie stérile: La Reproduction, Esprit, 398, 1970; Baudelot e Establet, L'école capitaliste en France, Paris, Maspero, 1972; R. Sainsalieu, Sur La Reproduction de P. Bourdieu e J.-C. Passeron, Revue Francaise de Sociologie, VII, 3, jul./sept. 1973, além do artigo de Vincent Petit, já mencionado. pelos herdeiros), será erigido "como a linguagem da razão, da cultura" como 'elemento' ou horizonte da Verdade (com V maiúsculo). O particular é arbitrariamente erigido em universal e o 'capital cultural' adquirido na esfera doméstica, pelos filhos da burguesia, lhes assegura um privilégio considerável no destino escolar e profissional. No destino, enfim" (p. 21).

Essas dimensões analíticas - além de outras que deixamos de mencionar -, destacadas por Prado Jr., passam totalmente desapercebidas pelos demais críticos, preocupados apenas em contabilizar o "potencial revolucionário" imediato que A Reprodução poderia apresentar.

A operação a que vimos aludindo torna-se inteligível a partir do estado do campo educacional à época. Provavelmente, a hipótese de trabalho mais promissora é a de que tal operação ocorre em um campo inclinado a demandas heterônomas ${ }^{6}$ e, correlativamente, atende à lógica concorrencial do campo na época: os defensores da dicotomia "reprodução x transformação" estavam, eles mesmos, embora nem todos, empenhados na construção de teorias pedagógicas bastante propensas à politização e militância, ${ }^{7}$ que fatalmente seriam questionadas por uma sociologia a qual, conquanto ainda em grande parte desconhecida no Brasil, apre-

${ }^{6}$ Demandas heterônomas são demandas externas, alheias à lógica do campo considerado. Sabe-se que campos autônomos são espaços concorrenciais de lutas relativamente independentes dos conflitos gerais da sociedade. Em um estado de reduzida autonomia, um campo apresenta fracas potencialidades de refratar os conflitos do espaço social geral (sobretudo os latentes). Portanto, encontra-se mais aberto às demandas externas, heterônomas (cf. Bourdieu, 1997). Esse não é o local adequado para desenvolver o argumento, mas o elevado grau de heteronomia do campo educacional brasileiro à época pode ser constatado na politização do mesmo.

7 "Iniciam-se no final dessa década [de 1970] outros esforços na linha das sugestões da teoria marxista que, não se satisfazendo com as teorias crítico-reprodutivistas, postulam a possibilidade de uma teoria crítica da educação que capte criticamente a escola como instrumento coadjuvante no projeto de transformação social" (Libâneo, 1991, p. 31). 
sentava-se como candidata à tarefa de desmistificar tanto os móveis de luta dos campos simbólicos quanto os otimismos decorrentes das disposições contestatárias dos agentes do campo educacional, tendentes a depositar suas esperanças de transformar o mundo pelas tomadas de consciência libertadora. Efetivamente, posta nesse âmbito, a Sociologia de Bourdieu, sem dúvida, estava condenada à perda de legitimidade num campo em crescente politização. Essa forma de deslocamento deve ser entendida a partir de uma configuração específica das forças analíticas que moldavam o campo educacional brasileiro à época e, por conseguinte, definiam e delimitavam os móveis legítimos das lutas inseparavelmente teóricas e práticas, pedagógicas e políticas.

A operação levada a termo no campo educacional brasileiro nos anos de 1980, e que acabaria por destinar a obra de Bourdieu a um lugar da análise educacional caracterizado pelo rótulo de "reprodutivista" ou "crítico-reprodutivista", estava dotada de cinco aspectos inseparáveis. Em primeiro lugar, deu-se pouca atenção ao arcabouço conceitual desenvolvido pelo sociólogo até a época, ou seja, os conceitos de habitus, campo, arbitrário cultural, capital simbólico, estratégia, poder simbólico, violência simbólica etc., e às operações conceituais e relacionais entre todos esses conceitos, como, por exemplo, a que estabelece a homologia entre os campos, a que define a lógica das práticas e a do mercado de bens simbólicos. Em segundo lugar, também não parece ter havido a consideração de um dos fundamentos da sociologia de Bourdieu, qual seja, o da existência das mediações e das autonomias relativas entre os campos. A conseqüência disso foi que a Bourdieu, empenhado em apreender a contribuição do sistema de ensino aos processos mais gerais de reprodução social, ou, como se diria hoje, o lugar da educação e do sistema de ensino numa economia geral das práticas e das trocas simbólicas, foi atribuída uma "teoria da educação" que, conquanto crítica e denunciadora, era não-dialética.

Essa suposta dimensão não-dialética conduz ao terceiro aspecto, qual seja, tudo indica ter havido o deslocamento da perspectiva sociológica de Bourdieu para uma perspectiva "sócio-lógica". As proposições do "livro um" de A Reprodução foram, na prática, e a despeito das declarações em contrário, cindidas das operações de pesquisa do "livro dois" e, conseqüentemente, tomadas como um discurso genérico sobre a escola, válido para todas as sociedades e em todas as épocas. ${ }^{8}$ Isso conduziu à idéia de um caráter nãodialético da teoria, ${ }^{9}$ na época a forma suprema de desqualificação epistemológica, forma decerto eufemizada de desqualificação política. Isso sugere que, em vez de se interpretar a obra do autor como uma tentativa científica de fundar uma antropologia das práticas e das trocas simbólicas a partir da análise de certas instituições das sociedades contemporâneas (o sistema de ensino, por exemplo), identificou-se nela tanto teses políticas, sobretudo sobre a escola, quanto esquemas puramente lógicos e aistóricos de interpretação "sócio-lógica".

O quarto aspecto está ligado à criação de expectativas em torno de propostas pedagógicas na obra do autor: na ausência de um discurso doutrinal sobre a educação, ela foi interpretada como "teoria da educa-

8 "Um esquema de interpretação inteiramente fechado sobre si mesmo" (Barreto, 1972, p. 99); "uma lógica do social, quer dizer, uma teoria da educação válida para todas as épocas e todas as sociedades que existiram, existem ou venham a existir" (Saviani, 1986, p. 16).

${ }^{9}$ Afirmava-se, assim como os críticos marxistas franceses de Bourdieu (Vincent Petit, Snyders, Baudelot e Establet etc.), que sua teoria ignorava a contradição: "a falta de uma perspectiva histórica [...] impede a colocação adequada das possibilidades dialéticas do sistema de ensino, que, se não chega a ser o elemento determinante da transformação de uma dada constelação de poder, pode contribuir de alguma maneira para que essa constelação se altere" (Barreto, 1972, p. 99). “A teoria não permitiria, assim, a apreensão das contradições, das lutas" (Cunha, 1979, p. 100; itálico do autor); "Mas a realidade movimenta-se, e a contradição é a base desse movimento. O próprio desenvolvimento do conceito [de eliminação] implica sua contraposição com o seu contrário. Bourdieu e Passeron não desconhecem isso, mas não exercitam essa dialética. Pelo menos não no texto em questão [A Reprodução]" (Freitas, 1991, p. 273). 
ção" sem propostas. Para um campo que se encontrava num estado no qual se dava bastante ênfase à ação, sobretudo transformadora, isso era interpretado como defeito grave da teoria. Finalmente, como complemento às demais operações, a obra de Bourdieu acabou por ser aprisionada nas dicotomias que ele tanto combateu e vem combatendo em suas pesquisas: enclausurou-se a sociologia de Bourdieu na dicotomia "reprodução $x$ transformação", dicotomia que na época fez enorme sucesso no campo educacional. ${ }^{10} \mathrm{O}$ resultado dessas

${ }^{10}$ Fenômeno similar ocorreu com a apropriação das idéias de Bourdieu na Inglaterra e nos EUA, quando sua obra foi enclausurada, respectivamente, nas dicotomias "reprodução x resistência" e "micro x macro" (cf. Bourdieu e Wacquant, 1992, p. 133). É interessante constatar que as apropriações da obra de Bourdieu no campo educacional brasileiro apresentam algumas semelhanças, e certamente muitas diferenças, em relação às verificadas no campo das ciências sociais anglo-americanas. Além do aprisionamento da obra do autor nas dicotomias mencionadas, observam-se outras analogias: o desconhecimento quase total das pesquisas publicadas nas Actes - "o volumoso corpus de estudos empíricos publicados na revista fundada por Bourdieu raramente é consultado por pesquisadores ingleses e americanos" (Wacquant, 1993, p. 244), enquanto no campo educacional brasileiro foram identificados apenas 27 textos com referências às Actes; uma certa fragmentação na leitura do autor verificada no campo educacional brasileiro, sobretudo no que diz respeito a $A$ Reprodução, é exemplificada na já referida leitura da parte um desse livro; leituras que aproximam Bourdieu ao marxismo, especialmente a Althusser - "A partir dos anos 60 uma nova corrente teórica, o neomarxismo, tem apresentado significativa produção, sobretudo na Europa Ocidental e em países subdesenvolvidos (por exemplo, Althusser, Baudelot e Establet, Bourdieu e Passeron, Bowles e Gintis)”(Gomes, 1983, p. 85); “Ao lado de Althusser, Bourdieu é outro influente estruturalista de orientação marxista que se dedicou especialmente ao estudo da educação e sua organização" (Sander, 1984, p. 52) - conquanto tenha havido pelo menos um alerta sobre essa aproximação: "espanto diante de interpretações da teoria [de Bourdieu] que procuravam 'encaixá-la' dentro de certos esquemas teóricos, alguns identificados até mesmo com as correntes tributárias da tradição marxista, sem perceberem os intérpretes que, assim fazendo, estavam, na realidade, construindo outra(s) teoria(s)" (Cunha, 1979, p. 79); e uma certa inclinação a considerar os trabalhos do sociólogo fran- interpretações conjuntas foi um Bourdieu absolutamente irreconhecível, transformado em "pedagogo reprodutivista" (Silva, 1996).

A literatura já se encarregou de refutar essas leituras, mas talvez caiba sublinhar que, no caso das resistências, tanto para o Bourdieu de hoje quanto para o de então, as resistências individuais e coletivas existem sempre, são componentes não elimináveis do processo de reprodução social. É, por conseguinte, um pleonasmo afirmar e insistir nas resistências dos agentes às coações sociais. $\mathrm{O}$ problema proposto por Bourdieu era (e é) inteiramente outro: era (e é) o de mostrar como se dá a forte adesão dóxica dos agentes sociais à ordem estabelecida e como o sistema de ensino, sobretudo a partir das formas de classificação escolarmente sancionadas e reproduzidas, está implicado nesta adesão, quer dizer, nessa cumplicidade impensada, pré-reflexiva, incorporada como uma "segunda natureza". Toda a discussão reprodução x resistência fica, a partir daí, destituída de sentido científico, embora tenha feito ponderável sentido político na época, em um campo educacional fortemente inclinado, conforme já se disse, à militância e à politização, como foi o caso brasileiro.

Nos anos de 1980, há também trabalhos que, sem partilhar das modalidades de leitura já descritas, apropriam-se de conceitos ou argumentos do autor. ${ }^{11} \mathrm{~A}$ partir

cês como excessivamente vinculados ao contexto político-social da França: “A visão crítico-reprodutivista surgiu basicamente a partir das conseqüências do movimento de maio de 68, a chamada tentativa de revolução cultural dos jovens, que teve sua manifestação mais retumbante na França” (Saviani, 1986, p. 15).

${ }^{11}$ Alguns exemplos: "O que queremos aproveitar de Bourdieu é sua idéia de que, sob a aparência de neutralidade com que se apresenta um sistema de ensino, está encoberta a distribuição diferencial do capital cultural entre as classes" (Covre, 1981, p. 123). Benakouche (1981) apóia-se em alguns resultados de P. Bourdieu e M. de Saint-Martin, "Le patronat", Actes, n 20/21, 1978, para rebater teses de Bresser Pereira sobre a tecnoburocracia. Nadai (1984) utiliza-se de noções retiradas de A economia das trocas simbólicas e A Reprodução para expressar o argumento segundo o qual o sistema de ensino impõe aos estudantes sistemas de pensa- 
de meados da década, começam a aparecer textos evidenciando uma forma de apropriação mais sistemática da obra de Bourdieu. Esses trabalhos contribuem, pouco a pouco, para tornar mais evidente toda a problemática científica suscitada por sua obra - podem ser citados, por exemplo, os trabalhos de Martins (1987, 1989), um sobre a teoria de Bourdieu e outro sobre a emergência, desenvolvimento e consolidação das instituições privadas no campo universitário. Porém, como o campo educacional brasileiro ainda se encontrava num estado no qual eram fortes as demandas heterônomas, o aprisionamento da obra de Bourdieu na dicotomia "reprodução x transformação" (ou "reprodução x resistência") ainda permanece dominante. Basta observar o texto de Freitas (1991), que, conquanto no âmbito de uma apropriação tópica, retoma a argumentação anteriormente desenvolvida sobretudo por Saviani: ${ }^{12}$ Bourdieu é necessário (crítico), mas não suficiente (desmobiliza e não aponta perspectivas para a ação transformadora dos agentes educacionais, para a luta de classes). ${ }^{13}$

mento "que os levam a agir segundo um certo código de normas e valores que os caracteriza como pertencentes a um certo grupo social ou classe" (p. 141). Motta (1986) vale-se de textos como o já mencionado "Le patronat" e "Le titre et le poste" (P. Bourdieu e L. Boltanski, Actes, n. ${ }^{\circ} 2$, 1975) para descrever os processos de reprodução tecnocrática na empresa e na escola, enfocados a partir de conceitos como os de capital cultural e habitus.

12 "Chamo de concepção crítico-reprodutivista a tendência que, a partir das análises dos determinantes sociais da educação, considera que a função primordial da educação é dupla: reprodução das relações sociais de produção e inculcação da ideologia dominante. É, pois, crítica já que postula que a educação só pode ser compreendida a partir dos seus condicionantes; e reprodutivista, uma vez que o papel da educação se reduz à reprodução das relações sociais, escapando-lhe qualquer possibilidade de exercer um influxo transformador. As principais teorias que expressam essa tendência são: a) teoria do sistema de ensino enquanto violência simbólica (Bourdieu e Passeron); b) teoria da escola enquanto aparelho ideológico do Estado (Althusser); c) teoria da escola dualista (Baudelot e Establet)" (Saviani, 1982, p. 59).

13 "Tem sido apontado com insistência na literatura o fato de Bourdieu e Passeron não considerarem a prática da escola na pers-
Observa-se que, nos anos 80, aumentam consideravelmente as menções a Bourdieu nos textos dos periódicos consultados (nesta década, publicam-se 125 artigos com referências a esse autor), ao mesmo tempo que seus textos, além de $A$ Reprodução, se tornam mais acessíveis, sobretudo ao público acadêmico, por conta de um mercado editorial chamado a responder às demandas do campo universitário, mormente da Sociologia e Antropologia que, aliás, não parecem ter participado do acantonamento de Bourdieu na problemática especificamente pedagógica da reprodução e transformação (ou resistência). Concomitante a lançamentos editoriais ocorridos ao longo de toda a década, em meados dos anos de 1980 aparecia o que possivelmente é a primeira tradução de um texto de Bourdieu nos periódicos do campo educacional brasileiro: tratase da entrevista "Universidade: os reis estão nus", na Revista Brasileira de Estudos Pedagógicos (v. 66, $\mathrm{n}^{\circ}$ 152). Registre-se também que, em 1989 , o periódico Educação em Revista, da Universidade Federal de Minas Gerais (UFMG), publicou "A escola conservadora: as desigualdades frente à escola e à cultura”. Só o fato de vir a lume dois textos de Bourdieu em periódicos do campo educacional já sugere uma perceptível alteração na configuração desse espaço social.

Efetivamente, para o final da década de 1980, a dicotomia "reprodução x transformação" vai envelhecendo aos poucos, envelhecimento concomitante ao declínio dos modos de análise então mais em voga no campo - pedagogia crítico-social dos conteúdos, pedagogia do oprimido e as variantes então praticadas de marxismo. Mas a problemática da reprodução e da

pectiva da 'contradição' envolvida nela. Isso valeu-lhes o título de crítico-reprodutivistas. Depois disso, tem-se lido mais a crítica desses autores do que seu trabalho original, como se não houvesse nada mais que aprender com eles. Acreditamos que este ensaio vá contribuir para mostrar que, apesar de a contribuição desses autores poder ser considerada insuficiente para dar conta de toda a realidade da escola, mesmo assim é uma contribuição que necessariamente deve ser levada em conta. Nossa opinião é que o trabalho de Bourdieu e Passeron é necessário, embora possa não ser suficiente" (Freitas, 1991, p. 272). 
transformação (ou resistência) persistiria, como dotada de inércia, e só iria sair de cena em meados da década de 1990. Um índice do quanto essa problemática foi dominante no campo educacional é o fato de trabalhos como os de Nogueira (1990) e Silva (1990), autores que desempenharam importante papel no cenário das apropriações brasileiras do sociólogo francês, ainda serem, nessa época, de certa forma tributários da problemática "reprodução x resistência".

A partir de meados dos anos de 1990, a obra de Bourdieu passa a receber leituras mais diversificadas, evidenciando tanto apropriações conceituais tópicas quanto do modo de trabalho: ${ }^{14}$ nessa década, são publicados nos periódicos 215 trabalhos com referências ao sociólogo. Isso é constatável na multiplicidade de objetos e temas nos quais seus conceitos são mobilizados e, sobretudo, na incorporação ativa do modus operandi da teoria, procedimento antecipado nos anos de 1980, como já mencionado, por alguns trabalhos, como os de Martins. Essa incorporação pode ser exemplificada nos textos de Nogueira (1991), Setton (1994) e Canêdo (1991), dentre outros. O fato é que a sociologia praticada por Bourdieu somente encontra espaço de inserção efetiva no campo da análise educacional quando do declínio dos modos de análise anteriormente citados e com a reativação dos estudos de sociologia da educação no país: leituras de Basil Bernstein e Bourdieu, nova sociologia da educação de Apple, teoria educacional crítica, estudos de currículo, revista Teoria \& Educação, avaliações do legado de Luiz Pereira e Marialice Foracchi; enfim, quando finalmente se instaura na análise educacional uma pluralidade de pesquisas sociológicas, em objetos e métodos. No decorrer da década de 1990, é possível encontrar, no campo educacional brasileiro, trabalhos inspirados em Bourdieu procurando dar conta de uma vasta gama de objetos, indicando em muitos casos, como já se disse,

${ }^{14}$ Exemplo de apropriação tópica pode ser encontrado em Santos e Oliveira (1995), que se utilizam do conceito de campo, de Bourdieu, para caracterizar as áreas do currículo e da didática como “campos de estudo e de práticas sobre a educação" (p. 122). não apenas o uso de um ou outro utensílio conceitual desenvolvido pelo sociólogo, mas a criativa incorporação de uma forma de fazer ciência. Deve também ser observado que, nos anos de 1990, são publicadas sínteses do pensamento de Bourdieu, algumas das quais situando a obra do autor no espaço da produção sociológica: Martins (1990), Silva (1992), Veiga Neto (1992; 1993), Vieira (1994), Castro (1995), Garcia (1996).

Algumas observações podem ainda ser feitas a propósito da diversidade das apropriações do pensamento de Bourdieu, nos anos de 1990, no campo educacional brasileiro. Uma das marcas principais dessas apropriações é justamente o esforço de mobilização dos conceitos e dos modos de trabalho do autor para a análise de questões específicas do espaço da educação. Tal é o caso dos estudos que investem na análise de temáticas como as relações entre origem social e expectativas profissionais de futuros professores ou das análises das relações que os professores (de português) mantêm com a questão da leitura. Esses trabalhos (Silva, 1997; Batista, 1998) incluem-se entre os sete artigos publicados por Educação em Revista entre 1997 e 1999. Ao atentarmos também à dimensão quantitativa da presença de Bourdieu na produção educacional recente, dois outros periódicos expressivos do campo evidenciam a sua força: a revista Educação \& Realidade abrigou, entre 1981 e 1997, 14 trabalhos em que o autor era referido; a revista Teoria \& Educação, igualmente do Rio Grande do Sul, publica, em apenas dois anos, cinco textos nas mesmas condições. Podese apreender na leitura da maioria desses textos, e em grande parte dos que aparecem nos outros periódicos na mesma época, disposição mais efetiva para apropriar-se do modo de trabalho, pondo-o à prova e evidenciando sua potencial fertilidade. Uma tal disposição significa, então, o abandono da insistência em buscar no autor apenas propostas de transformação social via educação. Livres dessa espécie de fixação que marcou de modo significativo a leitura dos anos de 1970 e parte dos de 1980, os estudos que se apoiam em Bourdieu e dele se apropriam passam a revelar a maior familiaridade com a obra: incorporam outros tí- 
tulos e outras contribuições do sociólogo e de seu grupo reunido em torno de seminários de pesquisas e o já mencionado periódico Actes. ${ }^{15}$

O que ainda se poderia acrescentar a essas observações diz respeito às peculiaridades do campo educacional brasileiro, no qual a produção científica esteve fortemente orientada para a resolução de problemas, que se acompanhou por um afã prescritivo e, em muitas circunstâncias, fez passar a um segundo plano a possibilidade de se estar compreendendo as especificidades do funcionamento do espaço no qual a educação se concretiza e no qual se disputa o direito de impor o discurso legítimo acerca da mesma. Silva (1992) mostrou isso ao assinalar a diferença entre os problemas educacionais e os problemas sociológicos da educação: não se trata de deixar de esperar conseqüências políticas práticas advindas das teorias, elas podem e devem ter tais conseqüências, sem que para isso as expectativas sobre as mesmas venham integrar a própria teoria. É também o caso de se indagar se essa marca da apropriação do pensamento de Bourdieu entre nós, nos anos de 1970 e parte dos de 1980, não constitui mesmo, e ainda hoje sob formas variadas, um dos traços principais da produção educacional, nos obrigando a indagar acerca dos rumos tomados por essa produção, no âmbito não somente da sociologia, mas da história, da psicologia e de estudos especialmente ligados à investigação do trabalho prático do ensino.

AFRÂNIO MENDES CATANI é doutor em sociologia pela FFLCH-USP e professor na Faculdade de Educação da USP. Autor de livros e artigos sobre sociologia da educação e da cultura, políticas de ensino superior na América Latina e história do cinema brasileiro, com destaque para: Sete ensaios sobre o Collège de France, São Paulo: Cortez, 1999, organizado em colaboração com Paulo Martinez e Reformas educacionais em Portugal e no Brasil, Belo Horizonte: Autêntica, 2000, organizado em colaboração com Romualdo Oliveira. E-mail: afraniocatani@usa.net.

${ }^{15}$ Exemplar dessa nova disposição de trabalho seria o texto “A escolha do estabelecimento de ensino pelas famílias; a ação discreta da riqueza cultural" (Nogueira, 1998).
DENICE BÁRBARA CATANI, doutora em educação, é professora associada (livre-docente) na Faculdade de Educação da USP. Autora de estudos acerca da história da educação brasileira, publicou, entre outros, os livros: Educação em Revista: a imprensa periódica e a história da educação, São Paulo: Escrituras, 1997, em co-autoria com Maria Helena Câmara Bastos; Docência, Memória e Gênero, São Paulo: Escrituras, 2000, 2. ed., em coautoria com Belmira Oliveira Bueno, Cyntia Pereira de Sousa e Maria Cecília Cortez Cristhiano de Souza. Atualmente, desenvolve, em colaboração, projeto de pesquisa apoiado pelo Convênio de Cooperação Internacional CAPES-ICCTI: "Estudos comparados sobre a escola - Brasil e Portugal - séculos XIX e XX". E-mail: dcatani@hotmail.com.

GILSON R. DE M. PEREIRA, doutor em educação pela USP, é professor na Faculdade de Educação da Universidade do Estado do Rio Grande do Norte. Publicações recentes: Centros e museus de ciências: visões e perspectivas, São Paulo, Saraiva, 1999, em colaboração; Taxionomias sociais do magistério oficial paulista; estudo a partir de necrológios, Cadernos de Pesquisa, $\mathrm{n}^{\circ}$ 110, jul. 2000; Regimes de valor, regimes de conhecimento: alguns temas da antieconomia da dádiva, Educação \& Sociedade, n ${ }^{\circ} 72$, ago. 2000; A servidão ambígua: valores e condições do magistério, São Paulo, Escrituras, 2001, no prelo. E-mail: gilrdemp@bol.com.br.

\section{Referências bibliográficas}

BARRETO, Elba de Sá, (1972). Resenha de La Reproduction. Cadernos de Pesquisa, no 4, p. 97-99, out.

(1975). Professores de periferia: soluções simples para problemas complexos. Cadernos de Pesquisa, n ${ }^{\circ}$ 14, p. 97109 , set.

BARROSO, Carmen L. de M., MELLO, Guiomar Namo de, (1975). $\mathrm{O}$ acesso da mulher ao ensino superior brasileiro. Cadernos de Pesquisa, n 15 , p. 47-77, dez.

BATISTA, Antônio Augusto G., (1998). A leitura incerta: a relação de professores(as) de português com a leitura. Educação em Revista, $\mathrm{n}^{\circ} 27$, p. 85-103, jul.

BENAKOUCHE, Rabah, (1981). Regulação econômica e formas de propriedade. Educação \& Sociedade, nº 9, p. 97-112, maio.

BOURDIEU, Pierre, (1987). Lecture, lecteurs, lettrés, littérature. In: BOURDIEU, P. Choses dites. Paris: Minuit, p. 132-143. 
As apropriações da obra de Pierre Bourdieu no campo educacional brasileiro, através de periódicos da área

(1993). The field of cultural production, or the economic world reversed. Poetics, 12, p. 311-356, nov.

(1997). Les usages sociaux de la science. Pour une sociologie clinique du champ scientifique. Paris: Editions INRA.

BOURDIEU, Pierre, CHARTIER, Roger, (1985). La lecture: une pratique culturel; débat entre Pierre Bourdieu et Roger Chartier. In: CHARTIER, Roger, (org.). Pratiques de la lecture. Paris: Rivages, p. 267-94.

BOURDIEU, Pierre, WACQUANT, Loïc, (1992). Réponses. pour une anthropologie réflexive. Paris: Ed. du Seuil.

CANÊDO, Letícia Bicalho, (1991). Estratégias familiares na produção social de uma qualificação política. Educação \& Sociedade, n 39, p. 221-245, ago.

CAPALBO, Creusa, (1974). A dimensão dialética do pensamento educacional. Revista Brasileira de Estudos Pedagógicos, v. 60, $n^{\circ} 134$, p. 218-226, abr./jun.

CASTRO, Magali, (1995). Contribuições da sociologia clássica e contemporânea para a análise das relações de poder na escola; um estudo do poder em Weber e em Bourdieu. Educação \& Sociedade, $\mathrm{n}^{\circ} 50$, p. 105-143, abr.

CATANI, Afrânio Mendes, (1999). Algumas lições da aula inaugural de Pierre Bourdieu. In: CATANI, A. M., MARTINEZ, P. H. (org.). Sete ensaios sobre o Collège de France. São Paulo: Cortez, p. 89-103.

CATANI, Afrânio Mendes, NOGUEIRA, Maria Alice, (1998). Uma sociologia da produção do mundo cultural e escolar. In: NOGUEIRA, Maria A., CATANI, Afrânio M., (org.). Pierre Bourdieu: escritos de educação. Petrópolis: Vozes, p. 7-15.

COVRE, Maria de Lourdes M., (1981). A formação do administrador; um estudo da educação enquanto técnica organizativa. Educação \& Sociedade, $\mathrm{n}^{\circ}$ 9, p. 113-137, maio.

CHARTIER, Roger, (1985) (org.). Pratiques de la lecture. Paris: Rivages.

(1998). Au bord de la falaise; l'histoire entre certitudes et inquiétudes. Paris: Albin Michel.

CUNHA, Luiz Antônio, (1979). Notas para uma leitura da teoria da violência simbólica. Educação \& Sociedade, n 4, p. 79-110, set.

(1982). A simbólica violência da teoria. Cadernos de Pesquisa, no 43, p. 55-57, nov.
DURAND, José C. Garcia, (1982). Torcidas de nariz a Bourdieu e Passeron. Cadernos de Pesquisa, no 43, p. 52-54, nov.

FREITAS, Luiz Carlos de, (1991). A dialética da eliminação no processo seletivo. Educação \& Sociedade, n 39, p. 265-85, ago.

GARCIA, Maria Manuela Alves, (1996). O campo das produções simbólicas e o campo científico em Bourdieu. Cadernos de Pesquisa, $\mathrm{n}^{\circ}$ 97, p. 64-72, maio.

GOERGEN, Pedro, (1986). A pesquisa educacional no Brasil: dificuldades, avanços e perspectivas. Em Aberto, no 31, p. 1-18, jul./set.

GOMES, Candido A. C., (1983). Enfoques teóricos em sociologia da educação. II - O paradigma do conflito. Fórum Educacional, v. 7, $\mathrm{n}^{\text {o } 3, ~ p . ~ 85-104, ~ j u l . / s e t . ~}$

GOUVEIA, Aparecida Joly, (1976). A escola, objeto de controvérsia. Cadernos de Pesquisa, n 16, p. 15-19, mar.

LIBÂNEO, José Carlos, (1991). A didática e as tendências pedagógicas. Idéias, nº 11, p. 26-36.

MARTINS, Carlos Benedito, (1987). Estrutura e ator: a teoria da prática em Bourdieu. Educação \& Sociedade, n 27, p. 34-46, set.

(1989). O novo ensino superior privado no Brasil (1964 - 1980). Revista Brasileira de Estudos Pedagógicos, v. 70, no 165 , p. 159-88, maio/ago.

(1990). A pluralidade dos mundos e das condutas sociais: a contribuição de Bourdieu para a sociologia da educação. Em Aberto, ano 9, n 46, p. 59-72. abr./jun.

MELLO, Guiomar Namo de, (1979). Fatores intra-escolares como mecanismos de seletividade no ensino de $1^{\circ}$ grau. Educação \& Sociedade, $\mathrm{n}^{\mathrm{o}} 2$, p. 70-8, jan.

(1983). Educação escolar e classes populares: uma reflexão sobre o atual momento educacional e político no Brasil. $A N D E, \mathrm{n}^{\circ} 6$, p. 5-9.

MICELI, Sergio, (1987). A força do sentido. In: MICELI, S. (org.). Pierre Bourdieu: a economia das trocas simbólicas. $2^{\text {a }}$ ed. São Paulo: Perspectiva, p. I-LXI.

(1999). Um intelectual do sentido. Folha de S. Paulo, 7 fev. Caderno Mais!

MOTTA, Fernando C. Prestes, (1986). Tecnoburocracia e educação formal. Educação \& Sociedade, n 23, p. 50-78, abr. 
NADAI, Elza, (1984). O ensino de história no $2^{\circ}$ grau: problemas, deformações e perspectivas. Educação \& Sociedade, $\mathrm{n}^{\circ} 19$, p. 134-46, dez.

NOGUEIRA, Maria Alice, (1990). A sociologia da educação no final dos anos 60/início dos anos 70: o nascimento do paradigma da reprodução. Em Aberto, n 46, p. 49-58, abr./jun.

(1991). Trajetórias escolares, estratégias culturais e classes sociais. Teoria \& Educação, no 3, p. 89-112.

(1998). A escolha do estabelecimento de ensino pelas famílias: a ação discreta da riqueza cultural. Revista Brasileira de Educação, nº 7, p. 42-56, jan./abr.

ORTIZ, Renato, (1983). A procura de uma sociologia da prática. In: ORTIZ, R. (org.). Pierre Bourdieu: sociologia. São Paulo: Ática, p. 7-36.

PETIT, Vincent, (1982). As contradições de "A Reprodução". Cadernos de Pesquisa, $\mathrm{n}^{\circ}$ 43, p. 43-51, nov.

PINTO, Louis, (2000). Pierre Bourdieu e a teoria do mundo social. Rio de Janeiro: Editora Fundação Getúlio Vargas.

PRADO JR., Bento, (1980). A educação depois de 1980, ou cem anos de ilusão. In: et al. Os descaminhos da educação. São Paulo: Brasiliense, p. 9-30.

SANDER, Benno, (1984). A administração da educação como processo mediador. Revista Brasileira de Administração da Educação, v. 2, no 1 , p. 38-62, jan./jun.

SANTOS, Lucíola L. de Castro P., OLIVEIRA, Maria Rita Neto S., (1995). Currículo e didática. Idéias, n 26, p. 121-37.

SAVIANI, Dermeval, (1982). Escola e democracia: para além da "teoria da curvatura da vara". ANDE, no 3, p. 57-64. (1983). Escola e democracia. São Paulo: Cortez. (1986). A pedagogia histórico-crítica no quadro das tendências críticas da educação brasileira. ANDE, no 11, p. 15-23.
SETTON, Maria da Graça J., (1994). Professor: variações sobre um gosto de classe. Educação \& Sociedade, no 47, p. 73-96, abr.

SILVA, Lizete S., (1997). Origem social e expectativas profissionais de licenciados: uma discussão introdutória. Educação em Revista, no 20/25, p. 74-85, dez. 1994, jun. 1997.

SILVA, Tomaz T., (1990). Retomando as teorias da reprodução. Teoria \& Educação, $\mathrm{n}^{\circ}$ 1, p. 155-179.

(1992). A dialética da interioridade e da exterioridade em Bernstein e Bourdieu. Teoria \& Educação, no 5, p. 133148

(1996). Bourdieu e a educação. In: Identidades terminais: as transformações na política da pedagogia e na pedagogia da política. Petrópolis: Vozes, p. 229-235.

VIEIRA, Luiz Renato, (1994). Entre o sociologismo e o individualismo: considerações sobre a sociologia de Pierre Bourdieu. Educação \& Filosofia, v. 8, nº 16, p. 285-300, jul./dez.

VEIGA NETO, Alfredo J., (1992). A ciência em Kuhn e a sociologia de Bourdieu: implicações para a análise da educação científica. Educação \& Realidade, v. 17, n 1, p. 93-107, jan./jul.

(1993). A teoria de ciência em Kuhn e a sociologia de Bourdieu: as diferenças. Educação \& Realidade, v. 18, nº 2, p. 57-61, jul./dez.

VELLOSO, Jacques, (1985). Dependência e educação comparada. Educação \& Sociedade, no 22, p. 105-119, set.

WACQUANT, Loïc, (1993). Bourdieu in America: notes on the transatlantic importation of social theory. In: CALHOUN, Craig, LIPUMA, Edward, POSTONE, Moishe (orgs.). Bourdieu critical perspectives. Cambridge: Polity Press, p. 235-262.

WHITAKER, Dulce, (1994). Escola, violência e trabalho infantil no Brasil. Idéias, n 21, p. 55-66. 


\section{Anexo \\ Referências à obra de Pierre Bourdieu em periódicos educacionais brasileiros}

\author{
REVISTA DA ANDE \\ (ANDE, São Paulo)
}

Operação escola: uma proposta governamental para erradicar a evasão no ensino primário, Luciana de Mello Gomide, nº 3, 1982.

Escola e democracia: para além da "teoria da curvatura da vara", Dermeval Saviani, no 3, 1982.

Educação escolar e classes populares: uma reflexão sobre o atual momento educacional e político do Brasil, Guiomar Namo de Mello, nº 6, 1983.

O ensino básico e o processo de democratização da sociedade brasileira, Dermeval Saviani, $n^{\circ}$ 7, 1984.

A educação vista pelo analfabeto, Margot Campos Madeira, $n^{\circ} 8,1984$.

A pedagogia histórico-crítica no quadro das tendências críticas da educação brasileira, Dermeval Saviani, nº 11, 1986. Avaliação educacional escolar: para além do autoritarismo, Cipriano Carlos Luckesi, nº 11, 1986.

Trabalho, educação e tecnologia: treinamento polivalente ou formação politécnica?, Gaudêncio Frigotto, nº 14, 1989.

\section{CADERNOS CEDES}

(CEDES, Universidade Estadual de Campinas, Faculdade de Educação)

Privatização: a política do estado autoritário para o ensino superior, Carlos Benedito Martins, no 5, 1981.

Perfil do supervisor necessário, Newton Cesar Balzan, $n^{\circ} 7$, 1982.

Projeto Nezahualpill: uma alternativa curricular para a educação de crianças das classes populares, Regina de Assis, $\mathrm{n}^{\circ}$ 9, 1984.

Investigación participativa y cultura popular: una experiencia en curso, Sérgio Martinic e Héctor I. Sáinz, n 12, 1984.

A pesquisa nas ciências sociais - considerações metodológicas, Maria da Glória M. Gohn, nº 12, 1984.

A leitura do mundo precede a leitura da palavra, Sarita Maria A. Moysés, no 14, 1985.
Formação do jovem professor para a educação básica, Nilda Alves, n 17, 1986.

O público e o privado na educação superior brasileira nos anos 80, Carlos Benedito Martins, n 25, 1991.

A produção recente na área da educação, Silke Weber, $n^{\circ} 27$, 1992.

De rótulos, carimbos e crianças nada especiais, Maria Ângela Monteiro Corrêa, no 28, 1992.

A autonomia universitária e escolar e a formação do professor: Uruguai e Brasil, Célia Frazão Soares Linhares, n 31, 1993.

Notas históricas sobre o grupo de trabalho "Sociedade e educação na América Latina" da ANPEd, Célia Frazão Soares Linhares e Maria Ciavatta Franco, nº 31, 1993.

$\mathrm{O}$ projeto pedagógico das escolas de samba e o acesso à cidadania - o caso da Mangueira, Filippina Chinelli, $n^{\circ} 33$, 1993.

Fundo de memória: infância e escola em famílias negras de São Paulo, Neusa Maria M. de Gusmão, no 42, 1997.

Reflexões sobre a filosofia e a cozinha, Agueda B. Bittencourt Uhle, n 42, 1997.

Memória social e cidadania, Julieta Beatriz R. Desaulniers, $n^{\circ} 42,1997$.

A leitura de romances no século XIX, Maria Arisnete C. de Morais, n 45, 1998.

A violência no imaginário dos agentes educativos, Alice Itani, $\mathrm{n}^{\circ} 47,1998$.

Meninos e meninas: expectativas corporais e implicações na educação física escolar, Eustáquia Salvadora de Sousa e Helena Altmann, nº 48, 1999.

\section{CADERNOS DE PESQUISA (Fundação Carlos Chagas)}

Resenha de La Reproduction, Elba S. de Sá Barreto, nº 4, out. 1972.

Professores de periferia: soluções simples para problemas complexos, Elba S. de Sá Barreto, no 14, set. 1975.

$\mathrm{O}$ acesso da mulher ao ensino superior brasileiro, Carmen Lúcia de M. Barroso e Guiomar Namo de Mello, n 15, dez. 1975.

A escola, objeto de controvérsia, Aparecida Joly Gouveia, no 16 , mar. 1976. 
Origem social, escolaridade e ocupação, Aparecida Joly Gouveia, nº 32, fev. 1980.

Educação e ideologia, Carlos R. Jamil Cury, n 35, nov. 1980.

A contribuição da educação técnica à mobilidade social, Maria Aparecida C. Franco e Cláudio Moura Castro, nº 36, fev. 1981.

Educação, cultura e poder: hipóteses sobre a importância da educação para o desenvolvimento, Pedro Demo, $n^{\circ} 41$, maio 1982.

Escuela, marginalidad y contextos en Colombia, Robrigo Parra Sandoval e Leonor Zubieta, nº 42, ago. 1982.

As teorias da educação e o problema da marginalidade na América Latina, Dermeval Saviani, nº 42, ago. 1982.

As contradições de A Reprodução, Vincent Petit, $\mathrm{n}^{\circ} 43$, nov. 1982.

Torcidas de nariz a Bourdieu e Passeron, José Carlos Durand, n 43, nov. 1982.

A simbólica violência da teoria, Luiz Antônio Cunha, no 43, nov. 1982.

Fracasso escolar: uma questão social, Terezinha Carraher e Analúcia D. Schlliemann, nº 45, maio 1983.

Classes e pedagogia: visível e invisível, Basil Bernstein, n 49, maio 1984.

Para um projeto de escola indígena: algumas interrogações metodológicas, Priscila F. Barbosa, no 50, ago. 1984.

A criança carente vista por suas professoras, Cecília Loreto Mariz, n 53, maio 1985.

A pedagogia do feminino. Análise de um ritual de apresentação da menina à sociedade, Alice Inês de Oliveira e Silva, no 54, ago. 1985.

Orientações teórico-metodológicas da sociologia da educação no Brasil, Aparecida Joly Gouveia, nº 55, nov. 1985.

Pigmalião na sala de aula: quinze anos sobre as expectativas do professor, Vânia Maria M. Rasche e Vera Maria M. Kude, nº 57, maio 1986.

Cultura, escola, ideologia e cognição: continuando o debate, Terezinha Carraher, David W. Carraher e Analúcia D. Schliemann, no 57 , maio 1986.

Os jovens e as mudanças estruturais na década de 70: questionando pressupostos e sugerindo pistas, Felícia Reicher Madeira, no 58, ago. 1986.
O "ofício de criança": definição social da primeira infância e funções diferenciais da escola maternal, Jean-Claude Chamboredon e Jean Prévot, nº 59, nov. 1986.

Os livros-texto do primário intensivo para adultos: principais interesses e opiniões de seus usuários, Cayetano de Lella, $n^{\circ}$ 61, maio 1987.

A classificação de "cor" nas pesquisas do IBGE: notas para uma discussão, Tereza Cristina Araujo, no 63, nov. 1987.

Do campo à cidade. As transformações nas práticas educativas familiares, Jerusa Vieira Gomes, nº 64, fev. 1988.

E os movimentos de professores da rede pública?, Angelina Teixeira Peralva, $n^{\circ}$ 64, fev. 1988.

Influências teóricas no ensino e currículo no Brasil, Terezinha Roserley da Silva, nº 70, ago. 1989.

Reciprocidade e hierarquia: relações de gênero na periferia de São Paulo, Cynthia A. Sarti, nº 70, ago. 1989.

Da crítica à tolerância: uma visão da educação de adultos na América Latina, Hugo Lovisolo, nº 70, ago. 1989.

Escrita: na história, na vida, na escola, Mary Julia M. Dietzsch, no 71 , nov. 1989.

Jeito de freira: estudo antropológico sobre a vocação religiosa feminina, Miriam Pillar Grossi, nº 73, maio 1990.

O lugar da tradição na modernidade latino-americana: etnicidade e gênero, Lia Zanotta Machado, nº 77, maio 1991. A produção recente na área da educação, Silke Weber, $n^{\circ} 81$, maio 1992.

Uma infância de curta duração: trabalho e escola, Tânia Dauster, no 82, ago. 1992.

Formação do administrador da educação no Brasil: uma tentativa de periodização, Flávia O. Corrêa Werle, nº 82, ago. 1992.

As novas tecnologias e as relações estruturais entre educação e produção, Tomaz Tadeu da Silva, no 87, nov. 1993.

A escolarização do doméstico. A construção de uma escola técnica feminina (1946-1970), Guacira Lopes Louro e Dagmar Meyer, no 87, nov. 1993.

O ambiente da criança, Terezinha Nunes, nº 89, maio 1994. Eugênia, loucura e condição feminina, Rita Cristina C. de Medeiros Couto, nº 90, ago. 1994.

Socialização primária: tarefa familiar?, Jerusa Vieira Gomes, nº 91, nov. 1994. 
Currículo: tensões e alternativas, Alícia Catalano de Bonamino e Zaia Brandão, no 92, fev. 1995.

Contribuição da sociologia para a avaliação escolar, Menga Lüdke, nº 92, fev. 1995.

Comparação entre a pós-graduação profissional e a acadêmica, Maria Rita Loureiro e José Carlos Durand, nº 94, ago. 1995.

A representação social do adolescente e da adolescência: um estudo em escolas públicas, Leila Maria Ferreira Salles, no 94, ago. 1995.

Relação com o saber e com a escola entre estudantes de periferia, Bernard Charlot, nº 97, maio 1996.

Ensino com pesquisa: a prática do professor universitário, Maria Isabel da Cunha, $n^{\circ}$ 97, maio 1996.

O campo das produções simbólicas e o campo científico em Bourdieu, Maria Manuela Alves Garcia, nº 97, maio 1996.

Conflitos teóricos na evolução da didática, Maria Cristina Davini, $n^{\circ}$ 98, ago. 1996.

O ensino superior privado no Distrito Federal, Carlos Benedito Martins, $\mathrm{n}^{\circ}$ 102, nov. 1997.

Educação e ciências sociais no Brasil: possíveis relações, Vera Maria Henriques, nº 103, mar. 1998.

Conselhos municipais de educação: estudo genético-histórico, Flávia Obino C. Werle, nº 103, mar. 1998.

A “construção” da escola do interior, Zélia D. Mediano, $\mathrm{n}^{\circ}$ 103, mar. 1998.

A instituição escolar e a violência, Marília Pontes Sposito, no 104, jul. 1998.

O binômio comunicação e educação: coexistência e competição, Luiz R. Busato, n 106, mar. 1999.

Por um política da branquidade, Henry A. Giroux, n 107 , jul. 1999.

Avaliação e política educacional: o processo de institucionalização do SAEB, Alícia Bonamino e Creso Franco, no 108 , nov. 1999.

Diagnósticos psicossociais de crianças e adolescentes na FEBEM de São Paulo, Rita de Cássia Pereira Lima, n 108 , nov. 1999.

Relações entre família e escola e suas implicações de gênero, Maria Eulina Pessoa da Carvalho, nº 110, jul. 2000.

Taxionomias sociais do magistério oficial paulista: estudo a partir de necrológios, Gilson R. de M. Pereira, nº 110, jul. 2000 .

\section{CONTEXTO E EDUCAÇÃO}

(Universidade de ljuí)

Educação popular x educação escolar: uma questão polêmica, José Luiz Piôto D’Ávila, no 4, out./dez. 1986.

Tendencias de la cultura y la cultura popular en la educación popular, Marco Raúl Mejía Jiménez, nº 9, jan./mar. 1988.

Escuela y culturas, Marco Raúl Mejía Jiménez, no 15, jul./ set. 1989.

Da forma da fala à forma gráfica da escrita. Uma análise lingüística do processo de alfabetização, Daniel Alvarenga, Magda Becker Soares et al., nº 16, out./dez. 1989.

A pedagogia histórico-crítica: ponto e contraponto, Eunice S. Trein e Neise Deluiz, nº 20, out./dez. 1990.

O CIEP como inovação educacional, Ana Cristina Leonardos, nº 22, abr./jun. 1991.

Intelectuais e autoritarismo no Brasil pós-64, Luiz Renato Vieira, no 24, out./dez. 1991.

Derechos humanos, sujetos y educación, Adriana Puiggrós, no 25, jan./mar. 1992.

"Se der tempo a gente brinca". O lúdico e o lazer da criança que trabalha e estuda, Paulo Cesar R. Carrano, n 29, jan./ mar. 1993.

As revistas de divulgação científica e a transmissão do conhecimento: uma abordagem sobre o ensino informal de ciências, Renato José de Oliveira, nº 32, out./dez. 1993.

A comparabilidade dos sistemas escolares; extravios e promessas para o novo século, Celia Frazão Soares Linhares, n 33 , jan./mar. 1994.

A comparação como indagação historicizada da realidade. Idéias para repensar o emprego da comparação na educação, Elisabete Cruvello da Silveira, nº 33, jan./mar. 1994.

Notas sobre la mirada antropológica en la educación, Jorge Osorio Vargas, nº 40, out./dez. 1995.

Educación, posmodernidad y después, Roberto A. Follari, n 41 , jan./mar. 1996.

Os movimentos sociais e a construção da escola (do sonho) possível, Roseli Salete Caldart, n 41, jan./mar. 1996.

Questiones teórico-metodológicas sobre investigación en educación en América Latina y la formación del pedagogo, Roberto A. Follari, nº 42, abr./jun. 1996.

Hacia una ciencia social histórica, Emilio Tenti Fanfani, n 43 , jul./set. 1996. 
La sistematización desde la perspectiva interpretativa, Alfonso Torres Carrilho, n 44 , out./dez. 1996.

A formação do trabalhador em educação e a organização do trabalho escolar: limites e perspectivas dos planos de educação, Ione Ribeiro Valle, nº 46, abr./jun. 1997.

Parâmetros curriculares e cultura: pensando ambigüidades, Rosália Maria Duarte, no 47, jul./set. 1997.

Ensino-aprendizagem: a persistente complexidade da dimensão política, Mary Rangel, nº 52, out./dez. 1998.

A qualificação do bancário na era da informática. Um estudo de caso sobre o treinamento dos caixas no Banco do Brasil, Maria da Conceição Silva-Freitas, nº 53, jan./mar. 1999.

La creencia en el progresso: un mito que desafia nuestra realidad?, Maria Teresa Bosio, nº 53, jan./mar. 1999.

\section{EDUCAÇÃO \& FILOSOFIA}

(Universidade Federal de Uberlândia)

Nota: para quê?, Reinaldo Matias Fleuri, v. 1, no 2, jan./ jun. 1987.

Problemas práticos e metodológicos da pesquisa qualitativa, Dietmar K. Pfeiffer, v. 5/6, nº 10/11 jan./dez. 1991.

Quem é o aluno da escola noturna?, Elisabeth da Fonseca Guimarães, v. 6, nº 12, jan./dez. 1992.

Novas questões para a alfabetização, Osvaldo Freitas de Jesus, v. 7, nº 14, jul./dez. 1993.

Justificativas para a institucionalização da linguagem pedagógica como distorção social, Tania Maria Marinho Sampaio, v. 8, nº 15, jan./jun. 1994.

Entre o sociologismo e o individualismo: considerações sobre a sociologia de Pierre Bourdieu, Luiz Renato Vieira, v. $8, n^{\circ} 16$, jul./dez. 1994.

A imprensa periódica educacional; as revistas de ensino e o estudo do campo educacional, Denice Barbara Catani, v. 10,

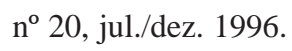

Psicologia, identidade social e cidadania: o espaço da educação e os movimentos sociais, Almir del Prette e Zilda A. P. del Prett, v. 10, no 20, jul./dez. 1996.

Curriculum y siglo XXI: hacia una recuperacion de los valores, Roberto A. Follari, v. 13, n 25, jan./jun. 1999.
EDUCAÇÃO \& REALIDADE

(Faculdade de Educação da UFRGS)

Aspectos sociológicos da alfabetização, Arabela Campos Oliven, v. 6, nº 3, set./dez. 1981.

A alfabetização: um enfoque filosófico, Rejane M. M. Carrion, v. 6, nº 3, set./dez. 1981.

Brasil: a educação que temos na democracia em que vivemos. Educação formal para quem?, Dermeval Saviani, v. 8, no 2, maio/ago. 1983.

Educação e trabalho: da profissionalização à preparação para o trabalho, Maria Helena Menna Barreto, v. 9, $\mathrm{n}^{\mathrm{o}}$ 1, jan./ abr. 1984.

Alguns pressupostos que sustentam o atual conceito de superdotado, Cecília Irene Osowski, v. 10, no 3, set./dez. 1985.

Reprodução e contradição: escola e classes populares, Norma Marzola, v. 11, nº 1, jan./jun. 1986.

Vendo a educação de forma relacional: classe e cultura na sociologia do conhecimento escolar, Michael W. Apple e Lois Weis, v. 11, nº 1, jan./jun. 1986.

Produção cultural é diferente de reprodução cultural é diferente de reprodução social é diferente de reprodução, Paul Willis, v. 11, nº 2, jul./dez. 1986.

A educação e o estado capitalista: contribuições e contradições, Roger Dale, v. 13, nº 1, jan./jun. 1988.

Distribuição do conhecimento escolar e reprodução social, Tomaz Tadeu da Silva, v. 13, nº 1, jan./jun. 1988.

El papel de las demandas populares por educación: el caso del movimiento sindical argentino, Daniel Filmus, v. 13, n 2 , jul./dez. 1988.

Educação e teorias da resistência, Mariano F. Enguita, v. 14, $\mathrm{n}^{\circ}$ 1, jan./jun. 1989.

Poder, conocimiento y sistemas educacionales: un modelo de análisis y cinco proposiciones para un programa de investigación sobre transmisión cultural escolar en Chile, Cristián Cox, v. 14, nº 1, jan./jun. 1989.

A escola e a produção da sociedade, André Petitat, v. 14, $\mathrm{n}^{\circ}$ 2, jul./dez. 1989.

Currículo e poder, Michael W. Apple, v. 14, no 2, jul./dez. 1989. 
Formación de educadores para el trabajo com sectores populares. Una experiencia en la universidad, Silvia Busilovsky, v. 16, $\mathrm{n}^{\circ}$ 1, jan./jul. 1991.

A ciência em Kuhn e a sociologia de Bourdieu: implicações para a análise da educação científica, Alfredo J. Veiga Neto, v. 17, no 1, jan./jul. 1992.

A avaliação do ensino e do aprender na universidade: controle, dissimulação ou (re)construção coletiva, Sônia Maria M. Ogiba, v. 17, nº 2, jul./dez. 1992.

A educação superior dentro dos planos do governo, Kira Tarapanoff, v. 17, nº 2, jul./dez. 1992.

Reconstruções convergentes com avanços: a interdisciplinaridade, Terezinha Maria V. Flores, v. 18, nº 1, jan./jun. 1993. Desconstruindo o construtivismo pedagógico, Tomaz Tadeu da Silva, v. 18, nº 2, jul./dez. 1993.

Abordagem sociológica do sujeito epistêmico, Nadja Mara H. Prestes, v. 18, nº 2, jul./dez. 1993.

A escola na televisão: quem se reconhece na "Escolinha do professor Raimundo"?, Rosa Maria B. Fischer, v. 18, nº 2, jul./dez. 1993.

A teoria da ciência em Kuhn e a sociologia de Bourdieu: as diferenças, Alfredo J. Veiga Neto, v. 18, nº 2, jul./dez. 1993. Estrutura versus subjetividade nas relações sociais: uma oposição de exterioridade?, Norberto Jacob Etges, v. 19, nº1, jan./jul. 1994.

O capricho das disciplinas, Rosa Maria B. Fischer, v. 19, no 2, jul./dez. 1994.

Didática e obstáculo pedagógico, Gilson R. de M. Pereira, v. 19, nº 2, jul./dez. 1994.

Famílias de camadas médias e a escola: bases preliminares para um objeto em construção, Maria Alice Nogueira, v. 20, $\mathrm{n}^{\circ}$ 1, jan./jun. 1995.

O campo da didática no ensino superior: um enfoque sóciohistórico, Maria Manuela Alves Garcia, v. 20, nº 1, jan./ jun. 1995.

O pós-estruturalismo de Foucault e a pesquisa de observação: um estudo das relações de poder na educação, Jennifer M. Gore, v. 20, nº 1, jan./jun. 1995.

Uma reforma educativa para as novas classes médias, Julia Varela, v. 20, nº 1, jan./jun. 1995.

Gênero, história e educação: construção e desconstrução, Guacira Lopes Louro, v. 20, nº 2, jul./dez. 1995.
O que é esta coisa chamada amor. Identidade homossexual, educação e currículo, Deborah P. Britzman, v. 21, nº 1, jan./ jun. 1996.

Notas para uma genealogia do curriculum escolar, Flávia Terigi, v. 21, nº 1, jan./jun. 1996.

As abordagens sociológicas do currículo: orientações teóricas e perspectivas de pesquisa, Jean-Claude Forquin, v. 21, $\mathrm{n}^{\circ} 1$, jan./jun. 1996.

Lutas entre culturas no currículo em ação da formação docente, Marlucy Alves Paraíso, v. 21, nº 1, jan./jun. 1996.

Instituição escolar e formação, Julieta Beatriz R. Desaulniers, v. 21, nº 2, jul./dez. 1996.

Conhecimento escolar: processos de seleção cultural e de mediação didática, Alice Ribeiro C. Lopes, v. 22, nº 1, jan./ jun. 1997.

Representaciones sociales y trajectorias educativas. Una relación problemática, José Antonio Castorina e Carina Viviana Kaplan, v. 22, nº 2, jul./dez. 1997.

Decifra-me ou te devoro: a excelência do objeto pela construção do argumento, João Paulo Pooli, v. 23, nº 2, jul./dez. 1998.

Notas sobre a cultura do nosso tempo: reflexões a partir das contribuições de Gramsci e Adorno/Horkheimer, João Valdir Alves de Souza, v. 24, nº 2, jul./dez. 1999.

Experiência de gestão ambiental no currículo de $1^{\circ}$ grau, Maria Flávia Carvalho Guazzinelli, América Cézar e Ana Lúcia formigli, v. 24, nº 2, jul./dez. 1999.

\section{EDUCAÇÃO E SELEÇÃO \\ (Fundação Carlos Chagas)}

A divisão interna da universidade: posição social das carreiras, Sergio Costa Ribeiro e Ruben Klein, ${ }^{\circ}$ 5, jan./jun. 1982.

Relações do vestibular com o sistema de ensino, Clarice Nunes, nº 12, jul./dez. 1985.

A escola de $2^{\circ}$ grau no Estado do Rio de Janeiro (ou quando a maioria não conta para a construção da cidade), Sergio Costa Ribeiro et al., $n^{\circ} 13$, jan./jun. 1986.

Escopo da seletividade ao ensino superior, José Camilo dos Santos Filho, no 13, jan./jun. 1986. 


\section{EDUCAÇÃO \& SOCIEDADE}

\section{(CEDES, Faculdade de Educação da Unicamp)}

Educação brasileira: problemas, Dermeval Saviani, $\mathrm{n}^{\circ} 1$, set. 1978.

Ideologia e intelectuais em Gramsci, Carmen Sylvia V. Moraes, $n^{\circ} 1$, set. 1978.

Fatores intra-escolares como mecanismos de seletividade no ensino de $1^{\circ}$ grau, Guiomar Namo de Mello, $n^{\circ} 2$, jan. 1979.

A crise da escola na sociedade capitalista contemporânea, Ana Mércia M. Silva et al., nº 2, jan. 1979.

As vicissitudes da ciência nacional, Regina Lúcia de M. Morel, nº 2, jan. 1979.

Eva viu a luta. Algumas anotações sobre a pedagogia do oprimido e a educação do colonizador, Carlos Rodrigues Brandão, no 3, maio 1979.

As organizações burocráticas e a sociedade, Fernando C. Prestes Motta, no 4, set. 1979.

Aspectos sociais da didática universitária, Michel Thiollent, no 4, set. 1979.

Notas para uma leitura da teoria da violência simbólica, Luiz Antônio Cunha, nº 4, set. 1979.

Tecnocracia e escola, César A. Ramos, nº 5, jan. 1980.

Códigos lingüísticos e estilos cognitivos, Bárbara Freitag, $\mathrm{n}^{\circ}$ 6, jun. 1980.

Regulação econômica e formas de propriedade, Rabah Benakouche, $\mathrm{n}^{\circ}$ 9, maio 1981.

A formação do administrador. Um estudo da educação enquanto técnica organizativa, Maria de Lourdes M. Covre, $\mathrm{n}^{\circ}$ 9, maio 1981.

Considerações críticas a respeito da orientação vocacional, Celso João Ferretti, no 10, set. 1981.

Sobre Educação e desenvolvimento social no Brasil: crítica da crítica e autocrítica, Luiz Antônio Cunha, nº 10, set. 1981.

Pedagogo, psicólogo escolar e análise experimental do comportamento: limitações ideológicas e perspectivas, Luiz Carlos de Freitas, n 13, dez. 1982.

"Yes, nós temos bananas" ou "Paraíba não é Chicago não". Um estudo sobre a alienação e o ensino de inglês como língua estrangeira, Luiz Paulo da M. Lopes, nº 13, dez. 1982. O ensino de história no $2^{\circ}$ Grau: problemas, deformações e perspectivas, Elza Nadai, nº 19, dez. 1984.
Desacertos da educação rural: o professor e o ensino rural, Maria Aparecida de Queiroz, nº 20, jan./abr. 1985.

O estudo da classe média na sociologia da educação, Arabela Campos Oliven, nº 21, maio/ago. 1985.

Dependência e educação comparada, Jacques Velloso, $\mathrm{n}^{\mathbf{0}}$ 22, set. 1985.

Tecnoburocracia e educação formal, Fernando C. Prestes Motta, n 23, abr. 1986.

O computador na escola: parte da solução ou parte do problema?, Michael W. Apple, no 23, abr. 1986.

A acumulação do capital simbólico, Beatriz Couto e Gama, no 25, dez. 1986.

Educação libertadora: utopia e alienação na escola particular, Maria Tereza Papaléo, Rosetta Mammarella e Dorilda Grolli, nº 26, abr. 1987.

Introdução à evolução das idéias pedagógicas no Brasil, Paulo Ghiraldelli Jr., nº 26, abr. 1987.

Estrutura e ator: a teoria da prática em Bourdieu, Carlos Benedito Martins, n 27 , set. 1987.

Democratización de la educación: proceso y perspectivas, Daniel Filmus, no 30, ago. 1988.

O esporte na educação e na política pública, Alba Zaluar, no 38, abr. 1991.

El intelectual contra el experto. Sobre la formación y las funciones del profesorado, Blas Cabrera Montoya, n 39, ago. 1991.

Educação e bem-estar social, Vanilda Paiva, n 39, ago. 1991.

Estratégias familiares na produção social de uma qualificação política, Letícia Bicalho Canêdo, no 39, ago. 1991.

A dialética da eliminação no processo seletivo, Luiz Carlos de Freitas, no 39, ago. 1991.

Políticas de educación superior: categorías para su análisis, Cristián Cox, no 40, dez. 1991.

Internalização: seu significado na dinâmica dialógica, Ana Luiza B. Smolka, no 42, ago. 1992.

Hacia una educación secundaria de caráter bivalente: condición de mayor equidad social e desarollo económico, Victor Manuel Gómez, no 44, abr. 1993.

Qualificação, qualidades e qualificações, Nadya Araújo Castro, n 45, ago. 1993.

O novo paradigma de desenvolvimento: educação, cidadania e trabalho, Vanilda Paiva, no 45, ago. 1993. 
Professor: variações sobre um gosto de classe, Maria da Graça J. Setton, no 47, abr. 1994.

A instituição escolar e a escolarização: uma visão de conjunto, Jean-Michel Chapoulie e Jean-Pierre Briand, $n^{\circ}$ 47, abr. 1994.

Teatro experimental do negro: projeto político-pedagógico, Ricardo Gaspar Müller, no 49, dez. 1994.

Vestibular: cultura e tragédia, Francisco J. Pimenta Rocha, $\mathrm{n}^{\circ}$ 50, abr. 1995.

Contribuições da sociologia clássica e contemporânea para a análise das relações de poder na escola. Um estudo do poder em Weber e em Bourdieu, Magali Castro, nº 50, abr. 1995. La búsqueda de alianzas en educación, Juan Casassus, nº 52 , dez. 1995.

De algumas obscuridades epistemológicas para uma ciência barroca, Jacques Gauthier, nº 55, ago. 1996.

A arte de se ligar às coisas da cultura: escola e lei de retorno do capital simbólico, Gilson R. de M. Pereira, n 60, dez. 1997.

Trajetória escolar: investimento familiar e determinação de classe, José Luis P. D’Ávila, nº 62, abr. 1998.

Eufemismo e cumplicidade objetiva nos primórdios do campo educacional brasileiro: um caso exemplar de 1860, Gilson R. de M. Pereira, nº 66, abr. 1999.

\section{EDUCAÇÃO EM DEBATE \\ (Faculdade de Educação da Universidade Federal do Ceará)}

As desigualdades educacionais do nordeste como um fenômeno estrutural, Maria Nobre Damasceno, no 6/7 jul./dez. 1984.

Por uma concepção dialética da educação, Maria Nobre Damasceno, no 9, jan./jun. 1985.

Escola democrática e administração democrática da educação para uma nova ordem social ( $1^{\mathrm{a}}$ Parte: escola para a ordem estabelecida - uma crítica), José Camilo dos Santos, $n^{\circ}$ 15/16, jan./dez. 1988.

Formação do profissional de educação: necessidades sociais e princípios básicos, Maria Estrêla Araújo Fernandes, n 27/28, jan./dez. 1994.

O imaginário da violência: a casa e a rua, Daniel Lins, $\mathrm{n}^{\circ}$ 35, 1998.
O militante clandestino: memória, identidade e família, José Geraldo Vasconcelos, n 36, 1998.

Quem tem medo da mídia?, Daniel Lins, nº 37, 1999.

\section{EDUCAÇÃO EM REVISTA \\ (Faculdade de Educação da \\ Universidade Federal de Minas Gerais)}

Educação escolar e classes populares, Guiomar Namo de Mello, no 1, jul. 1985.

Prática docente na escola de $1 .^{\circ}$ grau: interesses, conflitos e possibilidades de mudança, Maria Inês de Matos Coelho, $n^{\circ} 4$, dez. 1986.

Mulheres mineiras da República Velha. Profissão: professora primária, Léa Pinheiro Paixão, nº 14, dez. 1991.

O currículo escolar e a realidade do cotidiano, Ângela Imaculada L. de Freitas Dalben, no 15, jun. 1992.

$\mathrm{O}$ ensino da leitura e suas condições de possibilidades escolares, Antônio Augusto Gomes Batista, nº 15, jun. 1992. A integração lingüística como objeto de ensino-aprendizagem da língua portuguesa, Maria da Graça Costa Val, $n^{\circ} 16$, dez. 1992.

O universitário de origem trabalhadora e as normas acadêmicas, Écio Antônio Pontes, nº 16, dez. 1992.

El peronismo y la enseñanza religiosa obligatoria en las escuelas publicas: 1943-1955, Cecília A. Pitelli e Miguel Somoza Rodriguez, nº 17, jun. 1993.

Relações interétnicas, religião e identidade: a proposta educativa de um grupo negro católico, Ana Lúcia E. F. Valente, no 18/19, dez. 1993/jun. 1994.

Uma leitura da educação à luza das teorias sociológicas de Émile Durkheim, Max Weber e Talcolt Parsons: um ensaio de interpretação, João Valdir Alves de Souza, nº 20/25, dez. 1994/jun. 1997.

A análise do poder em instituições educacionais: a presença de Max Weber na sociologia da educação de Pierre Bourdieu, Magali de Castro, no 20/25, dez. 1994/jun. 1997.

Origem social e expectativas profissionais de licenciados: uma discussão introdutória, Lizete Scalzilli da Silveira, no 20/25, dez. 1994/jun. 1997.

A fonte oral e a pesquisa em história da educação: algumas considerações, Diana Gonçalves Vidal, no 27, jul. 1998. 
História da educação e literatura: algumas idéias e notas, Eliane Marta Teixeira Lopes, no 27, jul. 1998.

A leitura incerta: a relação de professores(as) de português com a leitura, Antônio Augusto Gomes Batista, n² 27, jul. 1998. Lectura y educación en la modernidad latinoamericana, Xavier Rodriguez Ledesma, no 28, dez. 1998.

O lugar social da licenciatura, Lizete Scalzilli da Silveira, no 28, dez. 1998.

O que professores de um curso de licenciatura pensam sobre ensino?, Júlio Emílio Diniz Pereira, nº 28, dez. 1998.

Gramsci, a disciplina e a organização da cultura, João Valdir Alves de Souza, n 29, jun. 1999.

A originalidade de Paulo Freire no pensamento educacional brasileiro, Marlene Ribeiro, no 29, jun. 1999.

A formação de professores leitores literários: uma ligação entre infância e idade adulta?, Graça Paulino et al, nº 30, dez. 1999.

\section{EM ABERTO}

(Instituto Nacional de Estudos e Pesquisas Educacionais do Ministério da Educação INEP/MEC)

Questões teóricas e práticas na pesquisa social e educacional, Maria Nobre Damasceno, nº 31, jul./set. 1986.

A pesquisa educacional no Brasil: dificuldades, avanços e perspectivas, Pedro Goergen, nº 31, jul./set. 1986.

A sociologia da educação entre o funcionalismo e o pósmodernismo: os temas e os problemas de uma tradição, Tomaz Tadeu da Silva, nº 46, abr./jun. 1990.

A sociologia crítica e educação - Contribuições das ciências sociais para a educação, Pedro Demo, $n^{\circ}$ 46, abr./jun. 1990.

A sociologia da educação no final dos anos 60/início dos anos 70: o nascimento do paradigma da reprodução, Maria Alice Nogueira, no 46, abr./jun. 1990.

A pluralidade dos mundos e das condutas sociais: a contribuição de Bourdieu para a sociologia da educação, Carlos Benedito Martins, nº 46, abr./jun. 1990.

Uma contribuição da história para uma história da educação, Eliane Marta Teixeira Lopes, nº 47, jul./set. 1990.

Representação e leitura crítica do mundo nos livros didáticos, Mary Rangel, nº 61, jan./mar. 1994.

Divisão - relações sociais de sexo e do trabalho, Helena Hirata, nº 65, jan./mar. 1995.

\section{ESTUDOS EM AVALIAÇÃO EDUCACIONAL (Fundação Carlos Chagas)}

Avaliação e organização do trabalho pedagógico: uma articulação incipiente, Benigna Maria de Freitas Villas Boas, no 8, jul./dez. 1993.

\section{FÓRUM EDUCACIONAL}

(Instituto de Estudos Avançados em Educação da Fundação Getúlio Vargas)

Teoria e prática do método de projetos em educação: análise de uma experiência, José Fagundes, v. 4, n² 2, abr./jun. 1980. Enfoques teóricos em sociologia da educação, Candido A. C. Gomes, v. 7, nº 2, abr./jun. 1983.

Enfoques teóricos em sociologia da educação. II - O paradigma do conflito, Candido A. C. Gomes, v. 7, nº 3, jul./set. 1983.

Enfoques teóricos em sociologia da educação. III - O paradigma do conflito, Candido A. C. Gomes, v. 8, nº 2, abr./jun. 1984.

Tendências da pesquisa em sociologia da educação na França: 1975-1983, Angela Cunha Neves, Jacqueline Eidelman e Polymnia Zagefka, v. 9, nº 1, jan./mar. 1985.

Administração participativa na educação: mito, tabu ou práxis?, Roberto Ballalai, v. 9, nº 3, jul./set. 1985.

Exigência societal e exigência comparatista em sociologia da educação, J. M. Berthelot, v. 10, nº 4, out./dez. 1986.

Universidade: um caminho difícil, Aracy Bezerra Palhano, v. $11, n^{\circ} 2$, abr./jun. 1987.

Critérios e instrumentos para a revisão da estrutura de currículos, Roberto Follari e Jesús Bervezo, v. 11, no 2, abr./ jun. 1987.

Jürgen Habermas, a hermenêutica e epistemologia das ciências do homem, Eduardo Diatahy B. de Menezes, v. 12, $\mathrm{n}^{\circ} 4$, out./dez. 1988.

Notas e subsídios para a análise do discurso (uma contribuição à leitura do discurso da administração), Roberto Ballalai, v. 13, nº 1-2, jan./maio 1989.

A abordagem didática do ensino de línguas estrangeiras e os mecanismos de dependência e de reprodução da divisão de classes, Roberto Ballalai, v. 13, nº 3, jun./ago. 1989. 
Modelo, produção e reprodução na ciência: as escolas na formação do campo científico no Brasil (séculos XIX-XX), Isidro Maria da Silva Alves, v. 14, nº 3, jun./ago. 1990. Fenomenologia e educação, Creusa Capalbo, v. 14, $\mathrm{n}^{\mathrm{o}} 3$, jun./ago. 1990.

\section{IDÉIAS}

(Fundação de Desenvolvimento Educacional São Paulo)

A leitura na sala de aula. As muitas faces de um leitor, João Wanderley Geraldi, nº 5, 1990.

Avaliação da aprendizagem: teoria, legislação e prática no cotidiano de escolas de $1 .^{\circ}$ grau, Sandra Maria Zákia Lian Sousa, $\mathrm{n}^{\circ} 8,1990$.

Teoria pedagógica: limites e possibilidades, Luiz Carlos de Freitas, nº 11, 1991.

O diretor e o cotidiano na escola, Antônio Joaquim Severino, $\mathrm{n}^{\mathrm{o}} 12,1992$.

Relações família e escola - continuidade/descontinuidade no processo educativo, Jerusa Vieira Gomes, nº 16, 1993.

A organização do trabalho como fundamento da administração escolar: uma contribuição ao debate sobre a gestão democrática da escola, Romualdo Portela de Oliveira, $\mathrm{n}^{\circ}$ 16, 1993.

Violência na escola, Dulce Whitaker, no 21, 1994.

Escola violência e trabalho infantil no Brasil, Dulce Whitaker, no 21, 1994.

Currículo, disciplina e interdisciplinaridade, Alfredo José da Veiga Neto, nº 26, 1995.

Currículo e didática, Lucíola Licínio de Castro P. Santos e Maria Rita Neto Sales Oliveira, nº 26, 1995.

Descrição de uma trajetória na/da avaliação educacional, Clariza Prado de Souza, no 30, 1998.

Formação contínua e obrigatoriedade de competências na profissão de professor, Philippe Perrenoud, nº 30, 1998.

\section{PRO-POSIÇÕES}

(Faculdade de Educação da Universidade Estadual de Campinas)

O pensamento da esquerda e a educação na República Brasileira, Dermeval Saviani, nº 3, dez. 1990.
Currículo em ação: buscando a compreensão do cotidiano da escola básica, Corinta Maria Grisolia Geraldi, v. 5, nº 3, nov. 1994.

Los talleres de apoyo escolar: una alternativa complementaria a los procesos educativos formales, Maria Alejandra Corbalán, v. 8, nº 1, mar. 1997.

\section{REVISTA BRASILEIRA DE ADMINISTRAÇÃO DA EDUCAÇÃO (ANPAE)}

Consenso e conflito na administração da educação, Benno Sander, v. 1, nº 1, jan./jun. 1983.

A qualidade do ensino elementar, o professor e a política, Rudolf Lenhard, v. 1, nº 2, jul./dez. 1983.

A administração da educação como processo mediador, Benno Sander, v. 2, nº 1, jan./jun. 1984.

Universidade: a luta pelo poder, Petrus Maria Ulasman e Luiz Felipe Meira de Castro, v. 3, nº 1, jan./jun. 1985.

A pesquisa em administração escolar no Brasil, Romualdo Portela de Oliveira e Afrânio Mendes Catani, v. 10, $\mathrm{n}^{\circ}$ 1, jan./jun. 1994.

\section{REVISTA BRASILEIRA DE EDUCAÇÃO (ANPEd)}

Leitura escolar. Entre pedagogia e sociologia, Anne-Marie Chartier, nº 0, set./dez. 1995.

Ensino e historiografia da educação. Problematização de uma hipótese, Clarice Nunes, nº 1, jan./abr. 1996.

Memória e autobiografia. Formação de mulheres e formação de professores, Cynthia P. de Sousa, Denice B. Catani, Maria Cecília C. C. de Souza e Belmira O. Bueno, nº 2, maio/ago. 1996.

Estudos sobre juventude em educação, Marilia Pontes Sposito, no 5-6, maio/dez. 1997.

Jovens urbanos pobres. Anotações sobre escolaridade e emprego, Jerusa Vieira Gomes, nº 5-6, maio/dez. 1997.

Nota de leitura: Jovens - vida associativa e subjetividade, um estudo dos jovens do Jardim Oratório, de Marilena Nakano, Pedro Augusto H. Menin, no 5-6, maio/dez. 1997. A escolha do estabelecimento de ensino pelas famílias. A ação discreta da riqueza cultural, Maria Alice Nogueira, $\mathrm{n}^{\text {o }}$ 7, jan./abr. 1998. 
Bilingüismo e biculturalismo. Uma análise sobre as narrativas tradicionais na educação dos surdos, Carlos Skliar,

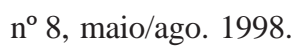

Movimentos em cena:... e as teorias por onde andam?, Ilse Scherer-Warren, nº 9, set./dez. 1998.

Resenha de Escritos de Educação, Rosário S. Genta Lugli e Paula Vicentini, no 9, set./dez. 1998.

Aprender e ensinar no cotidiano de assentados rurais em Goiás, Jadir de Morais Pessoa, nº 10, jan./abr. 1999.

Acerca do trabalho do professor: da tradução à produção do conhecimento no processo educativo, Luiza Cortesão e Stephen R. Stoer, no 11, maio/ago 1999.

\section{REVISTA BRASILEIRA DE ESTUDOS PEDAGÓGICOS (INEP/MEC)}

A dimensão dialética do pensamento educacional, Creusa Capalbo, v. 60, nº 134, abr./jun. 1974.

A formação do homem inacabado - ensaio de andragogia, Pierre Furter, v. 60, nº 134, abr./jun. 1974.

Uma proposta didática para a alfabetização de crianças das classes populares, Carmen Maria Craidy, Esther Pillar Grossi e Norma Regina Marzola Fialho, v. 64, n 148, set./ dez. 1983.

Reflexões sobre a educação de adultos como uma prática social do Estado, Helena Lewin, v. 65, nº 149, jan./abr. 1984. Travessia: tentativa de um discurso da ideologia, Magda Becker Soares, v. 65, nº 150, maio/ago. 1984.

Resenha de Ensino noturno - realidade e ilusão, de Célia Pezolo de Carvalho, Jader de Medeiros Britto, v. 65, nº 151, set./dez. 1984.

A diferente distribuição do saber escolar, Heliane Gramiscelli Ferreira de Mello, v. 66, nº 153, maio/ago. 1985. Resenha de Homo Academicus, de Pierre Bourdieu: Hélène Barros, v. 66, n 153, maio/ago. 1985.

Resenha de $O$ mito na sala de jantar, de Rosa Maria Bueno Fischer, Sérgio Dayrrel Porto, v. 66, nº 154, set./dez. 1985. Um modelo global de desenvolvimento teórico em sociologia da educação, Fred Mahler, v. 67, nº 157, set./dez. 1986. A propósito de uma sociologia crítica da educação, Michael Young, v. 67, nº 157, set./dez. 1986.

Para onde vai a sociologia da educação na França?, Viviane Isambert-Jamati, v. 67, n 157 , set./dez. 1986.
Um discurso científico sobre a educação em crise: a sociologia da educação na República Federal da Alemanha, Egon Becker, v. 67, nº 157, set./dez. 1986.

Avaliação qualitativa IV - sobre educação transformadora, Pedro Demo, v. 69, nº 161, jan./abr. 1988.

O novo ensino superior privado no Brasil (1964-1980.), Carlos Benedito Martins, v. 70, nº 165, maio/ago. 1989.

Educação indígena e bilingüismo - o caso do Acre, Nietta Lindenberg Monte, v. 73, nº 173, jan./abr. 1992.

A imprensa periódica especializada e a pesquisa histórica: estudos sobre o Boletim de Educação Pública e a Revista Brasileira de Estudos Pedagógicos, Diana Gonçalves Vidal e Marilena Jorge Guedes de Camargo, v. 73, n 175, set./ dez. 1992.

Acerca de como las mujeres llegaron a ser maestras (America Latina, 1870-1930), Silvia Cristina Yannoulas, v. $73, n^{\circ} 175$, set./dez. 1992.

Sobre a resenha "A crise dos paradigmas", de Waldemar de Gregori, Vera Maria Henriques, v. 74, n 176, jan./abr. 1993.

O movimento sindical na universidade pública brasileira, Pedro Rabelo Coelho, v. 74, n 178, set./dez. 1993.

Campo educacional: identidade científica e interdisciplinaridade, Vera Maria Henriques, v. 74, nº 178, set./dez. 1993. Ensino de ciências e capital lingüístico: notas para a construção de um objeto de pesquisa, Gilson R. de M. Pereira, João M. Pires e Maria da Conceição L. de Andrade, v. 75, no 179/180/181, jan./dez. 1994.

Cátedra e hegemonia da prática docente na Faculdade de Medicina da Universidade Federal de Minas Gerais, Léa Pinheiro Paixão, v. 76, nº 182/183, jan./ago. 1995.

O significado da educação superior para duas gerações de famílias de camadas médias, Geraldo Romanelli, v. 76, n ${ }^{\circ} 184$, set./dez. 1995.

O "estado" da educação na "folha" de jornal: como os jornais de grande circulação abordam a questão educacional, Belarmino Cesar Guimarães da Costa, v. 76, n 184, set./ dez. 1995.

Educação permanente: a saída para o trabalhador na era da qualidade total, Ana Shirley de França Moraes, v. 77, nº 185, jan./abr. 1996.

Sujeitos históricos: seus lugares na escola e na formação de professores, Célia Frazão Linhares, v. 77, n 185, jan./abr. 1996. 
Ciências humanas e educação: impasses para a superação dos paradigmas positivista e relativista, Renato José de Oliveira, v. 77, nº 185, jan./abr. 1996.

Memória e educação: O Espírito Victorioso, de Cecília Meireles, Yolanda Lima Lôbo, v. 77, nº 187, set./dez. 1996. Gênero e educação pública: uma comparação entre o CIEP e a escola comum, Alba Zaluar e Maria Cristina Leal, v. 78, no 188/189/190, jan./dez. 1997.

O veículo de circulação da pedagogia oficial da república: a Revista Pedagógica, José Gonçalves Gondra, v. 78, n 188/ 189/190, jan./dez. 1997.

Alegria na escola do trabalhador: um modelo pedagógico que satisfaça o trabalhador e lhe proporcione alegria no ato de aprender, Ana Shirley de França Moraes, v. 78, n 188/ 189/190, jan./dez. 1997.

Algumas observações sobre os Parâmetros Curriculares Nacionais - área de ciências, Gilson R. de M. Pereira, v. 78, no 188/189/190, jan./dez. 1997.

A pesquisa de representação social na área de ensino-aprendizagem: elementos do estado da arte, Mary Rangel, v. 79, n ${ }^{\circ}$ 193, set./dez. 1998 (publicado em abril 2000).

\section{REVISTA DA FACULDADE DE EDUCAÇÃO \\ (Faculdade de Educação da Universidade de São Paulo)}

O ensino de história no 2..$^{\circ}$ grau: problemas, deformações e perspectivas, Elza Nadai, v. 9, nº 1/2, 1983.

O ensino da língua materna: um grande desafio para a educação hoje, Maria Thereza Fraga Rocco, v. 10, nº 2, jul./ dez. 1984.

A questão pública da satisfação/insatisfação do professor no trabalho, Sonia Teresinha de Souza Penin, v. 11, nº 1/2, 1985. A dimensão do imaginário na problemática organizacional da educação, José Carlos de Paula Carvalho, v. 11, nº 1/2, 1985. Resenha de Coisas ditas, de Peirre Bourdieu por Afrânio Mendes Catani, v. 17, no 1/2, jan./dez. 1991.

Ensino de literatura e vestibular, Alice Vieira, v. 18, $\mathrm{n}^{\mathrm{o}} 2$, jul./dez. 1992.

Informação, disciplina e celebração: os anuários de ensino do Estado de São Paulo, Denice Barbara Catani, v. 21, nº 2, jul./dez. 1995.
Um estudo das relações de poder na escola pública de ensino fundamental à luz de Weber e Bourdieu: do poder formal, impessoal e simbólico ao poder explícito, Magali de Castro, v. 24, nº 1, jan./jun. 1998.

Retrato de corpo inteiro do Brasil: a cultura brasileira por Fernando de Azevedo, Libânea Nacif Xavier, v. 24, nº 1, jan./jun. 1998.

\section{TEORIA \& EDUCAÇÃO (Editora Ciências Médicas)}

Retomando as teorias da reprodução, Tomaz Tadeu da Silva, ${ }^{\circ} 1,1990$.

A caixa preta do hábito nas asas da história: reflexões críticas sobre a teoria da reprodução social, R. W. Connel, $\mathrm{n}^{\circ} 1$, 1990.

Como observar a reprodução, Elsie Rockwell, n 1, 1990. Reprodução, habitus e educação, Richard K. Harker, $n^{\circ}$ 1, 1990.

Reprodução, contradição, estrutura social e atividade humana na educação, Mariano F. Enguita, nº 1, 1990.

Paul Willis - educação, produção cultural e reprodução social, Liz Gordon, nº 1, 1990.

Para além da reprodução - entrevista com Claude Grignon, Julia Varela, $n^{\circ}$ 1, 1990.

Tornando-se uma matéria acadêmica: padrões de explicação e evolução, Ivor Goodson, nº 2, 1990.

Os paradigmas perdidos. Ensaio sobre a sociologia da educação e seu objetivo, André Petitat, no 3, 1991.

Educação escolarizada: violência simbólica ou prática libertadora? O caso brasileiro, Dulce Consuelo A. Whitaker, $\mathrm{n}^{\circ} 3,1991$.

Trajetórias escolares, estratégias culturais e classes sociais, Maria Alice Nogueira, nº 3, 1991.

A dialética da interioridade e da exterioridade em Bernstein e em Bourdieu, Tomaz Tadeu da Silva, no 5, 1992.

Saberes escolares, imperativos didáticos e dinâmicas sociais, Jean-Claude Forquin, no 5, 1992.

Entre história e sociologia: uma perspectiva construtivista aplicada à emergência dos colégios e da burguesia, André Petitat, nº 6, 1992.

Uma leitura da história da educação sob a perspectiva do gênero, Guacira Lopes Louro, nº 6, 1992. 
work and school education. The discourse of the subjects of the research reveals the conflict between the formation required for cooperative agricultural work and the model of basic education on which rural education is based.

\section{Isabel Lelis}

Profissão docente: uma rede de histórias

Este artigo tem o objetivo de analisar a identidade social do magistério das séries iniciais do ensino fundamental, forjada em processos de socialização familiar, escolar e profissional. Através do recurso às histórias de vida de treze professoras, foi possível perceber que muitos são os significados atribuídos ao trabalho docente. Recorrendo ao aporte da sociologia de Pierre Bourdieu, o trabalho permitiu compreender a constituição de habitus para a docência, as estratégias desenvolvidas pelas professoras para a conquista de títulos escolares, os modos de entrada na profissão, o peso da formação prévia e continuada nas formas como as professoras vivem e representam o trabalho que realizam. Considerando que a representação social do magistério, no contexto de uma escola de massa, foi alterada, o estudo acabou por problematizar imagens de passividade, negligência e incompetência que têm sido atribuídas às professoras pelas burocracias educacionais e agências governamentais.

The teaching profession: a webs of stories

This article proposes to analyse the social identity of teachers in the first series of primary education, forged through processes of professional, school and family socialization. Using the life stories of thirteen women teachers, the article discusses the significance attributed to the teaching profession. Taking Pierre Bourdieu's sociology as reference, the study explores the constitution of the habitus in teachers, the strategies they use to achieve academic qualifications, admission to the profession and the weight of initial and continued training in the way teachers experience and represent their work. This study challenges the images of passivity, negligence and technical incompetence that are attributed to teachers by educational authorities and governamental agencies, by recognizing that, at a time in which a massification of school is occuring, the social representation of teaching has been modified.

\section{Claudio Suasnábar}

Resistência, mudança e adaptação nas universidades argentinas: Problemas conceptuais e tendências emergentes no governo e na gestão acadêmica

$\mathrm{O}$ artigo propõe-se a fazer uma contribuição ao debate teóricometodológico dos referenciais conceptuais mais adequados para o estudo dos problemas do governo e da gestão universitária na Argentina.

Este trabalho também constitui uma primeira posta à prova do instrumental apresentado. São analisadas as tensões que geram as políticas estatais na gestão acadêmica. Considerase que a emergência de uma dupla linha de gestão e condução na institucionalização de novos atores nas universidades argentinas configuram os dois fenômenos que disputam o papel historicamente atribuído aos conselhos acadêmicos. Essas tensões, que hoje percorrem os processos de mudança institucional, expressam o conflito entre as novas formas de gestão e o modelo de co-governo que instaurou a Reforma Universitária de 1918.
Resistance, change and adaptation in argentine universities: concept problems and tendencies emerging from academic government and management

This article aims to contribute to the theoretical and methodological debate on the most suitable conceptual frameworks for studying the problems of government and management in Argentinian universities. The paper also constitutes a first test of the instruments presented therein. Tensions generated by state policies on academic management are also analysed. The article considers that the emergence of a double line of manegement and condut of the institution of new actors in Argentinian universities constitute the two phenomena which dispute the role historically attributed to academic councils. These tensions, which underlie processes of institutional change the, are the expression of conflicts between new forms of management and the model of cogovernment that established the Argentinian University Reform of 1918.

Afrânio Mendes Catani, Denice Bárbara Catani e Gilson R. de M. Pereira

As apropriações da obra de Pierre Bourdieu no campo educacional brasileiro, através de periódicos da área

A partir de pesquisa realizada em 20 periódicos especializados em educação, editados entre 1971 e 2000, são analisadas as formas de apropriação da obra de Pierre Bourdieu no campo educacional brasileiro. O conjunto dos 355 artigos publicados nesses periódicos que fazem referências ao sociólogo constitui o corpus básico para a análise das peculiaridades das interpretações brasileiras do autor. 
The appropriations of Pierre Bourdieu's work in the brazilian educational field

Based on research carried out in 20 specialised educational periodicals, published between 1971 and 2000, the present text analyses the forms of appropriation from Pierre Bourdieu's work in the field of Brazilian education. The set of 355 articles published in those periodicals that make reference to the sociologist constitutes the basic corpus for the analysis of the peculiarities of the Brazilian interpretations of this author.

Marcus Vinicius da Cunha

John Dewey e o pensamento educacional brasileiro: a centralidade da noção de movimento

$\mathrm{O}$ trabalho analisa artigos publicados em periódicos educacionais brasileiros entre 1930 e 1960, cujos temas são educação, democracia, filosofia, ciência e verdade, entre outros, desenvolvidos segundo concepções de Dewey. Em todos, ocupam posição central as noções de mudança e transformação, em oposição a estabilidade, fixidez e permanência. O objetivo é mostrar a relevância da noção de mundo em movimento, tanto para os brasileiros quanto para Dewey.

John Dewey and the brazilian educational thinking: the main position of the concept of change This paper analyses some articles published by educational journals in Brazil between 1930 and 1960, whose subjects are education, democracy, philosophy, science, truth and others, developed according to Dewey's ideas. In all of them, the main concept is the transformation of things, in opposition to steady. The central intent is to show the change of world like a key concept to the brazilian authors, as such as to Dewey.

\section{Sandra Mara Corazza}

Currículos alternativos/oficiais: o(s) risco(s) do hibridismo

$\mathrm{O}$ artigo enfatiza similaridades discursivas entre os PCNs do Ministério da Educação do Brasil, tidos como currículo oficial, e o Movimento Constituinte Escolar do governo petista do Rio Grande do Sul, proposto como currículo alternativo. Reflete sobre o que vem acontecendo com nossos currículos alternativos críticos, que acabam propondo quase a mesma educação que a do Governo Federal. Argumenta que, em função desse hibridismo, precisamos desfazer o risco de ligação, produzir e praticar currículos que ainda não existem, inventar mais uma vez a diferença.

\section{Alternative-official curricula: the} risk(s) of hybridism

The article stresses the discursive similarities between the National Curricula Parameters (PCN) established by the Brazilian Ministry of Education, considered the official curriculum, and the School Assembly Movement inspired by the Workers' Party state government in Rio Grande do Sul, proposed as an alternative curriculum. It discusses what has been happening with our critical alternative curricula which end up proposing almost the same education as that of the Federal Government. It forwards the argument that, as a consequence of this hybridism, we need to dispel the ambiguity, by producing and putting into practice curricula which do not yet exist and to invent once more the difference.

Reinaldo Matias Fleuri

Entre o oficial e o alternativo em propostas curriculares: para além do hibridismo

$\mathrm{O}$ texto discute a relação entre o oficial e o alternativo no discurso da Constituinte Escolar (1999-2000), pro- movida pelo governo do estado do Rio Grande do Sul (BR). Traz contribuições de pesquisadores em educação popular para interpelar os sujeitos (em particular os movimentos sociais populares e as instituições estatais) e discutir a metodologia utilizada neste processo de reformulação curricular. Enfatiza a importância da perspectiva complexa para se compreender os limites e as possibilidades de um processo oficial que pretende promover, paradoxalmente, a inserção dos movimentos sociais alternativos na formulação e no controle das diretrizes curriculares da escola pública.

Between the official and the alternative in curricular proposals: beyond hybridism

The text discusses the relationship between the official and the alternative discourse used in the School Assembly (1999-2000), sponsored by the state government of Rio Grande do Sul, in the south of Brazil. It presents contributions from researchers in the field of Popular Education with the purpose of inciting the subjects (specifically the popular social movements and state institutions) to reflect upon their practices and to discuss the methodology employed in this process of curriculum reform. It also emphasizes the significance of the complex perspective for understanding the limits and possibilities of an official process aimed at promoting, paradoxically, the participation of the alternative social movements in the formulation and control of curricular guidelines for the state school.

Creso Franco

O SAEB - Sistema de Avaliação da Educação Básica: potencialidades, problemas e desafios

Baseado em contribuição preparada no contexto da Comissão de Especialistas, 